\title{
Estimation of field-scale soil hydraulic and dielectric parameters through joint inversion of GPR and hydrological data
}

\author{
M.B. Kowalsky ${ }^{1}$, S. Finsterle ${ }^{1}$, J. Peterson ${ }^{1}$, S. Hubbard ${ }^{1}$, Y. Rubin ${ }^{2}$, E. Majer ${ }^{1}$, A. Ward ${ }^{3}$, \\ and G. Gee ${ }^{3}$ \\ ${ }^{1}$ Earth Sciences Division, Lawrence Berkeley National Laboratory, Berkeley, CA \\ ${ }^{2}$ Dept. of Civil and Environmental Engineering, University of California, Berkeley, CA \\ ${ }^{3}$ Hydrology Group, Pacific Northwest National Laboratory, Richland, WA
}

\begin{abstract}
A method is described for jointly using time-lapse multiple-offset cross-borehole ground-penetrating radar (GPR) travel time measurements and hydrological measurements to estimate field-scale soil hydraulic parameters and parameters of the petrophysical function, which relates soil porosity and water saturation to the effective dielectric constant. We build upon previous work to take advantage of a wide range of GPR data acquisition configurations and to accommodate uncertainty in the petrophysical function. Within the context of water injection experiments in the vadose zone, we test our inversion methodology with synthetic examples and apply it to field data. The synthetic examples show that while realistic errors in the petrophysical function cause substantial errors in the soil hydraulic parameter estimates, simultaneously estimating petrophysical parameters allows for these errors to be minimized. Additionally, we observe in some cases that inaccuracy in the GPR simulator causes systematic error in simulated travel times, making necessary the simultaneous estimation of a correction parameter. We also apply the method to a three-dimensional field setting using time-lapse GPR and neutron probe (NP) data sets collected during an infiltration experiment at the U.S. Department of Energy (DOE) Hanford site in Washington. We find that inclusion of GPR data in the inversion procedure allows for improved predictions of water content, compared to predictions made using NP data alone.
\end{abstract}




\section{Introduction}

Ground-penetrating radar (GPR) measurements are not directly related to soil hydraulic parameters in the vadose zone. However, they are highly sensitive to fluid distribution (and to changes thereof) and are therefore potentially useful for inferring soil hydraulic parameters. The use of GPR methods for characterizing the distribution and movement of fluids in the subsurface is well established. However, only recently has the potential for using time-lapse GPR measurements to infer soil hydraulic propertieswhich can then be used to model flow and transport-been explored [Binley et al., 2002; Kowalsky et al., 2004a; Lambot et al. 2004; Rucker and Ferre, 2004]. The response of a hydrological system to external stimuli, such as the injection of water in the subsurface or ponding of water on the ground surface, depends primarily on the soil hydraulic functions and their variations in space (and on the initial and boundary conditions). Corresponding GPR measurements of the same system also depend on the soil hydraulic functionsalthough indirectly - because the soil hydraulic functions influence the water distribution, which in turn influences the GPR response.

A review of GPR applications in hydrological investigations is given by Annan [2005]. The soil property that most directly affects the speed at which GPR waves travel in the subsurface is the (dimensionless) dielectric constant $\kappa$. For common earth materials (and under favorable conditions), it is related to the electromagnetic (EM) wave velocity (V) through

$$
V \approx \frac{c}{\sqrt{\kappa}}
$$

where $c$ is the EM wave velocity in free space [Davis and Annan, 1989]. The presence of water affects the dielectric constant of soil mixtures [Daniels, 1996] in a manner that can 
be modeled with relationships that are purely empirical [Topp et al., 1980, Persson et al., 2002], semi-empirical [Birchak et al., 1974; Roth et al., 1990], or theoretical [de Loor, 1964; Dobson et al., 1985; Friedman, 1998; Sihvola, 1999]. Hereafter, we refer to the functions that relate water content (or water saturation) to the dielectric constant of soil mixtures as petrophysical functions, and to the parameters that describe such functions as petrophysical parameters.

Because of their high sensitivity to the pore water distribution, cross-borehole ground-penetrating radar (GPR) measurements are used increasingly for monitoring transient flow processes in the vadose zone [e.g., Alumbaugh et al., 2002; Binley et al., 2001; Kowalsky et al., 2004b]. Tomographic inversion techniques [Peterson et al., 1985] are typically applied to cross-borehole GPR data sets [Eppstein and Dougherty, 1998; Peterson, 2001] to infer spatial distributions of EM velocity or dielectric constant (tomograms), which can be converted to water saturation with a petrophysical function. Tomogram artifacts (e.g., smoothing or smearing in the images), introduced through the tomographic inversion procedure, are potentially problematic for application to hydrological modeling [Stewart, 1991; Peterson et al., 2001]. Furthermore, while crossborehole tomograms are useful for gaining a qualitative understanding of the subsurface (e.g., to help identify preferential flow paths), in general they cannot be used to obtain quantitative estimates of vadose zone flow parameters, such as the permeability and the soil hydraulic parameters of the capillary pressure and relative permeability functions, except for in some limited cases [e.g., Hubbard et al., 1997].

Few studies have been published in which geophysical measurements are integrated in hydrological inversion in a fully coupled fashion (i.e., where the geophysical and 
hydrological measurements are simulated simultaneously and are linked explicitly to the hydrological parameters), especially for vadose zone applications. Hyndman et al. [1994, 1996] developed an inversion algorithm for estimating lithological zones and the hydrological parameters of the zones in fully saturated aquifers using seismic and tracer data. Rucker and Ferre [2004] used an analytical solution to invert for the average hydraulic conductivity value using the infiltration front position, inferred from GPR travel time measurements collected at a single depth (they also demonstrated the possibility of estimating two additional hydraulic parameters when including pressure head measurements).

Here we describe an approach for estimating soil hydraulic parameter distributions such as in the vadose zone through the coupled numerical simulation (and inversion) of multiple-offset cross-borehole GPR measurements and other hydrological measurements collected during transient flow experiments. Coupling between the hydrological and GPR simulators links the simulated water saturation and porosity distributions to the simulated GPR measurements (e.g., travel times), thus indirectly linking the geophysical observations to the soil hydraulic parameters. Joint inversion proceeds by perturbing the soil hydraulic parameters - which alters the simulated hydrological observations and the geophysical observations - until the simulated and measured geophysical and hydrological observations are in good agreement. A flow chart depicting the joint inversion procedure, which we implemented in iTOUGH2 [Finsterle, 1999], is given in Figure 1, and details of the inversion methodology are discussed below.

The methodology we employ is an extension of the work by Kowalsky et al. [2004a], who used geophysical and hydrological data jointly within a maximum a posteriori 
(MAP) inversion framework [McLaughlin and Townley, 1996] that employed concepts from the pilot point method [RamaRao et al., 1995; Gomez-Hernandez et al., 1997]. The approach of Kowalsky et al. [2004a] allowed for estimation of unknown log permeability values, at so-called pilot point locations, and other hydrological parameters, resulting in hydrological models that honored geophysical and hydrological data, and that contained permeability distributions with specified patterns of spatial correlation and that honored available log permeability point measurements. The method was shown to be useful for accurately predicting flow phenomena and quantifying parameter uncertainty. However, the forward model used to simulate GPR measurements was limited to a simple data acquisition configuration, disallowing the use of multiple-offset GPR measurements (discussed below) and three-dimensional models. In addition, the petrophysical function was assumed to be known and error free, despite the fact that inaccuracies easily enter into the field-scale petrophysical function when it is derived using non-site-specific data or laboratory-scale measurements [e.g., Moysey and Knight, 2004; Lesmes, 2005].

At present the aforementioned method of Kowalsky et al. [2004a] is extended to allow for 1) inclusion of GPR measurements (travel times) collected using any transmitter and receiver geometry within a possibly three-dimensional model, and 2) estimation of petrophysical parameters. We have also extended the method to allow for possible estimation of spatial correlation parameters, but this possibility is not currently explored herein. These extensions permit investigations under more realistic conditions (e.g., where there is uncertainty in the petrophysical function) and increase the flexibility of GPR data acquisition configurations that may be considered, which allows for soil hydraulic parameter estimates with increased resolution and accuracy. Following a 
description of the methodology, given in Section 2, synthetic examples and an application using field data are presented in Sections 3 and 4, respectively.

\section{Methodology}

\subsection{Hydrological measurements}

The hydrological process considered in this study is variably saturated flow in the vadose zone. Variably saturated flow of incompressible water in non-deformable porous media can be modeled with the Richards' equation:

$$
\varphi \frac{\partial S_{w}}{\partial t}+\nabla\left[\frac{K\left(S_{w}\right)}{\rho_{w} g} \nabla P^{c}\left(S_{w}\right)-K\left(S_{w}\right) \mathbf{z}\right]=0,
$$

where $K$ and $P^{c}$, both functions of water saturation $S_{w}$, are the unsaturated hydraulic conductivity and the capillary pressure, respectively, $\rho_{w}$ is the water density, $g$ is the gravitational constant, $\varphi$ is the porosity, and $\mathbf{z}$ is the vertically oriented unit vector (positive upward). The hydraulic conductivity is defined as:

$$
K=\boldsymbol{k} \frac{k_{r e l}\left(S_{w}\right) \rho_{w} g}{\mu_{w}},
$$

where $k_{r e l}$ is the dimensionless relative permeability (the only component of $K$ that is a function of water saturation), $\mu_{w}$ is the dynamic viscosity of water, and $\boldsymbol{k}$ is the absolute permeability, which is a scalar $k$ for the case of isotropic media, and which has horizontal and vertical components $k_{h}$ and $k_{v}$, respectively, for the case of anisotropic media. For this study, we model the relative permeability and capillary pressure with the functions given by van Genuchten [1980] as: 


$$
\begin{gathered}
k_{\text {rel }}=\sqrt{S}\left[1-\left(1-S^{m^{-1}}\right)^{m}\right]^{2} \\
P^{c}=-\alpha^{-1}\left(S^{m^{-1}}-1\right)^{1-m} \\
S=\frac{S_{w}-S_{w}^{r e s}}{S_{w}^{s a t}-S_{w}^{r e s}},
\end{gathered}
$$

where $S$ is the normalized water saturation, and $S_{w}^{r e s}$ and $S_{w}^{\text {sat }}$ are the soil-specific residual and maximum water saturation values, respectively, and $m$ (dimensionless) and $\alpha\left(\mathrm{Pa}^{-1}\right)$ are soil-specific parameters. Hysteresis of the relative permeability function can affect the redistribution of water following infiltration [Philip, 1991], but is not considered in this study.

To simulate flow in the vadose zone using (2)-(6), the soil hydraulic parameters $\varphi, \alpha$, $m, S_{w}^{r e s}, S_{w}^{s a t}$, and $\boldsymbol{k}$ must be specified. Although a number of studies suggest that spatial variability of these parameters can be significant [Jury et al., 1987; Russo and Bouton, 1992], data describing such variability for modeling applications are limited. In the present work, all parameters are considered spatially uniform, except for $\boldsymbol{k}$, which can be treated as a space random function (SRF).

The joint inversion approach described below aims to estimate the soil hydraulic parameters using a combination of hydrological measurements (e.g., water content values inferred from neutron probe logging) and ground-penetrating radar measurements (e.g., cross-borehole travel times), which are highly sensitive to the time- and space-varying distribution of $S_{w}$, which is in turn affected by the soil hydraulic parameters. The framework used for the coupled simulation (and inversion) of hydrological measurements and geophysical measurements (discussed next) is iTOUGH2 [Finsterle, 1999], a code 
that provides parameter estimation capabilities for the TOUGH2 flow simulator [Pruess et al., 1999].

\subsection{Ground-penetrating radar measurements}

\subsubsection{Petrophysical function relating water saturation and porosity to dielectric constant}

Application of GPR measurements in the subsurface requires a petrophysical function that relates the soil water saturation and porosity to the dielectric constant (e.g., reviews are given by Huisman et al. [2003] and Lesmes and Friedman [2005]). One of the most commonly used models, by Topp et al. [1980], is given as a third-order polynomial:

$$
\kappa=3.03+9.3 \theta+146.0 \theta^{2}-76.7 \theta^{3},
$$

where $\theta$ is the water content (the product of water saturation and porosity), and where the coefficients were determined through laboratory measurements on several inorganic soils. However, the dielectric constant of soils is sensitive to additional soil properties, such as the mineral composition of the solid soil particles [Roth et al., 1990], organic matter and bulk density [Jacobsen and Schjonning, 1993], temperature [Roth et al., 1990; Or and Wraith, 1999], and grain geometry and cementation [Lesmes and Friedman, 2005], all of which suggest the need for alternative petrophysical relationships that allow for sitespecific variations.

Alternatively, there are theoretically based models [Lesmes and Friedman, 2005], such as volumetric mixing formulae, which account for the volume fraction and geometrical arrangement of materials with known or measurable dielectric constants. An expression used for two-phase mixtures [Birchak et al., 1974] and extended to three- 
phase mixtures of air, water, and solids [Alharthi and Lange, 1987; Roth et al., 1990] is given by:

$$
\kappa=\left[(1-\varphi) \kappa_{s}^{n}+S \varphi \kappa_{w}^{n}+(1-S) \varphi \kappa_{a}^{n}\right]^{\frac{1}{n}},
$$

where $\varphi$ is the porosity, $\kappa_{s}$ is the dielectric constant for the solid components, $\kappa_{w}$ and $\kappa_{a}$ are the known dielectric constants for water and air, respectively, and $n$ is a parameter related to the geometric arrangement of materials relative to the applied electric field [Ansoult et al., 1984]. The value of $n$ is commonly assumed to be 0.5 , which is expected in isotropic media [Birchak et al., 1974], but measured values for sediments have been observed to range between 0.4 and 0.65 [Chan and Knight, 1999].

The petrophysical model (8) can be adjusted to site-specific conditions, given estimates of $\kappa_{\mathrm{s}}$ and $\varphi$. The measurement of porosity from cores can be problematic, since the in-situ packing of unconsolidated or semi-consolidated materials is difficult to preserve through the coring process. Values of $\kappa_{\mathrm{s}}$ are sometimes assumed (e.g., a "representative" value is taken from the literature) or are determined with cores in the laboratory using time-domain reflectometry (TDR) methods [Topp et al., 1980; Martinez and Byrnes, 2001]. However, errors can be unintentionally introduced from several sources during this process. As petrophysical functions are frequency dependent [Robinson et al., 2003, 2005], relationships derived in the laboratory from TDR measurements, for example, are not necessarily appropriate for application at the field scale [Huisman et al., 2003; Moysey et al., 2004], where the frequencies employed are typically lower than in the laboratory. Petrophysical functions may also be derived in the field by correlating dielectric constant estimates, derived from cross-borehole GPR, with estimates of water content inferred from co-located neutron probe (NP) data [Hubbard et 
al., 1997]. However, tomogram artifacts (such as smoothing) and errors in NP data [Yao et al., 2004; Fares et al., 2004] can introduce errors into the estimated petrophysical function [Huisman et al., 2003; Day-Lewis et al., 2004; Linde et al., 2005].

As will be described in Section 2.4, our inversion approach allows for estimation of petrophysical parameters in (8) - at present, we consider the estimation of $\kappa_{s}$-thus helping to overcome potential errors introduced by scale discrepancy and measurement error. It should be noted that we currently assume the error in the petrophysical function is contained entirely in the parameters, not in the petrophysical model itself.

\subsubsection{Simulation of GPR measurements}

Numerous techniques are available for simulating GPR measurements, ranging from ray-based methods [Cai and McMechan, 1995], to pseudo-spectral methods [Casper and Kung, 1996], to time-domain finite-difference full-waveform methods [Kunz and Luebbers, 1993; Bergmann et al., 1998]. Ray-based methods are the simplest and most computationally efficient for the simulation of GPR travel times; they are based on a high frequency approximation that calculates the arrival time of the first break of the transmitted wave (i.e., the time at which the wave amplitude departs from zero) and ignores the remainder of the waveform [Bregmen et al., 1989]. The straight-ray method was chosen for the current study for its computational efficiency. However, as will be discussed in the synthetic examples given below, significant errors can arise in travel times simulated using the straight-ray method, depending on the corresponding water distribution, leading in some cases to a systematic error (over-prediction) in simulated travel times that must be accounted for in the inversion procedure. 
The travel time $T$ for an EM wave traveling between the transmitting and receiving antennas in a domain characterized by discrete grid blocks can be approximated by defining a straight ray between the antennas and summing the travel times through each grid block that the ray travels:

$$
T=\sum_{i=1}^{N} \frac{L_{i}}{V_{i}}
$$

where $L_{i}$ is the length of the travel path (linear line segment) in block $i, N$ is the number of blocks through which the ray passes, and $V_{i}$ is the EM velocity in block $i$. For the present work, the petrophysical function is modeled using the volumetric mixing formula (8), which, through combination with (1) and (9), allows for the travel time $T$ to be calculated as follows:

$$
T=\sum_{i=1}^{N} \frac{L_{i}}{c}\left[\left(1-\varphi_{i}\right)\left(\kappa_{s}\right)^{n}+S_{w, i} \varphi_{i}\left(\kappa_{w}\right)^{n}+\left(1-S_{w, i}\right) \varphi_{i}\left(\kappa_{a}\right)^{n}\right],
$$

where $S_{w, i}$ and $\varphi_{i}$ are the water saturation and porosity in grid block $i$, respectively.

The simulation of cross-borehole GPR travel times in a domain undergoing transient fluid flow was made possible through solution of (10) within iTOUGH2 [Finsterle, 1999]. Each travel time is thus a function of the distributions of water saturation and porosity, the variable dielectric parameters $\left(n, \kappa_{\mathrm{s}}\right)$, and remaining known parameters.

\subsection{Joint inversion methodology}

Here we extend the method developed by Kowalsky et al. [2004a] for estimating flow parameter distributions in the vadose zone using hydrological and geophysical measurements collected during transient flow experiments. The approach used a maximum a posteriori (MAP) inversion framework [McLaughlin and Townley, 1996; 
Rubin, 2003] and employed concepts from the pilot point method [RamaRao et al., 1995; Gomez-Hernandez et al., 1997]. The permeability distribution was considered nonuniform and was treated as a lognormal SRF with a known pattern of spatial correlation (i.e., known semivariogram).

At present, in the case of non-uniform anisotropic permeability, the spatially varying component of permeability is introduced through the permeability modifier $\xi(x)$, defined through the following relationships:

$$
\begin{aligned}
& k_{v}(\mathbf{x})=k_{v} 10^{\xi(x)} \\
& k_{h}(\mathbf{x})=k_{h} 10^{\xi(x)}
\end{aligned}
$$

where $k_{v}$ and $k_{h}$ are the mean values of vertical and horizontal permeability, respectively, and $\xi(\mathbf{x})$ is an SRF with known patterns of spatial correlation (note that the methodology does not prevent the spatial correlation parameters from being treated as unknowns). The mean of $\xi(\mathbf{x})$ is zero and its variance is equivalent, as is the semivariogram, to that for the $\log$ distributions of $k_{h}(\mathbf{x})$ and $k_{v}(\mathbf{x})$. The remaining flow parameters are assumed to be spatially uniform and uncorrelated with permeability.

The permeability modifier field is parameterized using pilot points, giving a vector of unknowns $\left(\xi_{p p}\right)$ at the pilot point locations. Through sequential simulation [Deutsch and Journel, 1992], a permeability field conditional to $\xi_{p p}$ is generated. During the inversion procedure, estimates of $\xi_{p p}$ are repeatedly perturbed as the permeability fields are updated through sequential simulation, until the permeability field is found that provides 1) an optimal match to the observed hydrological and geophysical data, and 2) minimal deviation of the unknowns from prior estimates, if available. The remaining unknown model parameters are simultaneously estimated with $\xi_{p p}$. 
In previous work, the petrophysical function was assumed to be known and error free. In addition, the technique used for simulating ground-penetrating radar measurements was limited to one simple data acquisition configuration, the zero-offset profile (ZOP), in which the transmitting and receiving antennae are kept at equal depths during each measurement. This acquisition geometry yields a single depth profile of GPR travel times. While ZOP surveys are useful for gaining depth-averaged information, they do not provide information about lateral variations in material properties.

Here we use (10) to simulate GPR travel times for arbitrary transmitter and receiver positions (e.g., in multiple-offset profile surveys) within a model is possibly threedimensional with non-uniform grid spacing. Additionally, we expand the parameters that can be considered as unknowns to include the vector of soil hydraulic parameters, such as $\mathbf{a}_{\mathbf{h}}=\left[\phi, \alpha, m, S_{w}^{r e s}, S_{w}^{\text {sat }}, k_{h}, k_{v}, \ldots\right]$ from (2)-(6); the vector of petrophysical parameters $\mathbf{a}_{\mathbf{k}}$ $=\left[\kappa_{\mathrm{s}}, n\right]$ from (8); and, while not explored in this study, the vector of semivariogram parameters $\mathbf{a}_{\gamma}$, which could include, for example, the range parameter occurring in most semivariogram models [Deutsch and Journel, 1992]. These extensions permit investigations under more realistic conditions, such as where there is uncertainty in the petrophysical function or in the spatial correlation function. Moreover, improved accuracy and resolution can be obtained in the soil hydraulic parameter estimates using the wealth of data available in multiple-offset profile surveys.

The general goal of the inverse problem is the estimation of vectors $\mathbf{a}=\left[\mathbf{a}_{\mathbf{h}}, \mathbf{a}_{\mathfrak{k}}, \mathbf{a}_{\gamma}\right]$ and $\xi_{p p}$ given measurements of the following types:

1. GPR travel time measurements (T), given as $\left.\mathbf{z}_{G P R}=T_{G P R} \mid\left(\mathbf{x}_{T \times}^{*}, \mathbf{x}_{R x}^{*}, \mathbf{t}_{G P R}\right)\right\rfloor+\mathbf{v}_{G P R}$, taken at the transmitting and receiving antenna positions $\mathbf{x}_{T x}^{*}$ and $\mathbf{x}_{R x}^{*}$ (each of length $M_{G P R}$ ), 
and at survey times $\mathbf{t}_{G P R}$ (length $\left.N_{G P R}\right)$, that is, $\left(\mathbf{x}_{T x}^{*}, \mathbf{x}_{R x}^{*}, \mathbf{t}_{G P R}\right)=$ $\left(\mathbf{x}_{T x, i}, \mathbf{x}_{R x, i}, t_{G P R, 1}\right)_{i=1, \ldots, M_{G P R}}, \quad\left(\mathbf{x}_{T x, i}, \mathbf{x}_{R x, i}, t_{G P R, 2}\right)_{i=1, \ldots, M_{G P R}}, \ldots, \quad\left(\mathbf{x}_{T x, i}, \mathbf{x}_{R x, i}, t_{G P R, N_{G P R}}\right)_{i=1, \ldots, M_{G P R}}$, where $\mathbf{v}_{G P R}$ is the measurement error (length $M_{G P R} \times N_{G P R}$ ) associated with measurement of $\mathbf{z}_{G P R}$;

2. Hydrological measurements, given here as local water content measurements (e.g., inferred from NP measurements) $\mathbf{z}_{H}=\varphi\left(\mathbf{x}_{H}\right) \cdot S_{w}\left[\left(\mathbf{x}_{H}, \mathbf{t}_{H}\right)\right]+\mathbf{v}_{H}$, taken at borehole positions $\mathbf{x}_{H}$ (length $M_{H}$ ) and at survey times $\mathbf{t}_{H}$ (length $N_{H}$ ), where $\mathbf{v}_{H}$ is the measurement error (length $M_{H} \times N_{H}$ ) associated with measurement of $\mathbf{z}_{H}$.

In order to test the approach with minimal data requirements, we assume in this study that point measurements of permeability are unavailable, although they can easily be included if they are available [Kowalsky et al., 2004a]. However, as was mentioned above, we do assume that the geostatistical information describing the log permeability is known (e.g., the variance and additional semivariogram parameters).

Assuming that (a) the measurement errors are characterized by known normal distributions, (b) the permeability field is uncorrelated with other soil-hydraulic parameters, and (c) the prior information of the parameters is normally distributed, then the objective function (OF) that is minimized during inversion can be written as:

$$
\begin{gathered}
O F(\mathbf{a})=[\mathbf{z}-\boldsymbol{F}(\mathbf{a})]^{T} \mathbf{C}_{v}^{-1}[\mathbf{z}-\boldsymbol{F}(\mathbf{a})] \\
+\left[\xi_{p p}-\bar{\xi}_{p p}\right]^{T} \mathbf{C}_{\xi_{p p}}{ }^{-1}\left[\xi_{p p}-\bar{\xi}_{p p}\right] \\
+[\mathbf{a}-\overline{\mathbf{a}}]^{T} \mathbf{C}_{b}{ }^{-1}[\mathbf{a}-\overline{\mathbf{a}}]
\end{gathered}
$$

where $\xi_{p p}$ and $\overline{\mathbf{a}}$ are the prior means of $\xi_{p p}$ and $\mathbf{a}$, respectively, and $\mathbf{C}_{\xi_{p p}}$ and $\mathbf{C}_{b}$ are the corresponding covariance matrices. For the case in which log permeability point 
measurements are available, $\xi_{p p}$ and its variance values (which are used as the diagonal terms in $\mathbf{C}_{\xi_{p p}}$ ) are calculated through kriging [Deutsch and Journel, 1992]. For the case we currently consider in which no log permeability point measurements are available, the prior values of $\xi_{p p}$ equal zero (i.e., each pilot point is penalized in the same way for deviating from the mean $\log$ permeability value, which is one of the unknowns in $\mathbf{a}_{H}$ ); in addition, the values of $\mathbf{C}_{\xi_{p p}}$ contain the known $\log$ permeability variance, ensuring that the log permeability values at the pilot point locations stay reasonably close to the mean $\log$ permeability value $\boldsymbol{k}$.

For models with spatially uniform soil properties (as in the example given in Section 3.1), only one inversion realization is performed, giving MAP estimates that are equivalent to the weighed least squares solution. In models with heterogeneous permeability (as in the example given in Section 3.2 and the application to field data given in Section 4), multiple inversions are performed, each giving one realization of the MAP solution, and each obtained using a different initial log permeability field (i.e., a seed number that is unique to each inversion realization is used for sequential simulation [Deutsch and Journel, 1992]).

In the following examples, the Levenberg-Marquardt algorithm [Levenberg, 1944; Marquardt, 1963] was used to minimize the objective function.

\section{Synthetic examples}

The joint inversion methodology is demonstrated in this section using synthetic data collected during simulated water injections in the subsurface. The objective function (13) can be used to estimate all unknowns or some subset of unknowns, depending on the 
problem being considered. Here we test the effectiveness of the method for estimating various subsets of unknowns for two different heterogeneity conditions. In the first example (Section 3.1), we consider a model with spatially uniform soil parameters. In the second example (Section 3.2), we consider a model with a heterogeneous permeability distribution.

\subsection{Model with uniform soil hydraulic parameters}

The model considered in the first example has horizontal and vertical dimensions of 3 $\mathrm{m}$ and $4 \mathrm{~m}$, respectively, grid spacing of $10 \mathrm{~cm}$ (in both directions), and spatially uniform soil hydraulic properties (Figure 2). Boundary conditions are as follows: the total flux across the upper boundary, which represents the ground surface, is known; the lower boundary is fully saturated, representing the water table; and no-flow conditions are implemented at the vertical sides of the model. Because the steady-state water profile and the transient response to water injection depend on the hydraulic parameters, the simulation proceeds in two steps. First, the steady-state profile (gravity-capillary equilibrium) is simulated for the given set of hydraulic parameters. Second, using the steady-state profile to specify initial conditions, water injection and subsequent redistribution are simulated by imposing a mass flux of water equal to $1.08 \mathrm{~kg} / \mathrm{hr}$ at the injection point for 12 hours duration. See Table 1 for a list of parameters used in the simulation.

To test the inversion methodology, we simulated GPR and NP measurements before water injection (pre-injection) and several times after water injection $(18,24,36$, and 48 hours post-injection) in boreholes at horizontal positions of $1 \mathrm{~m}$ and $3 \mathrm{~m}$ (Figure 2). The 
synthetic NP measurements were obtained by recording the water content values during the simulation at the sampling locations shown in Figure 2a, and then adding measurement noise (zero-mean random deviates with standard deviation of 0.01 ).

To obtain the GPR measurements for the "true" model, a two-dimensional finite difference code was implemented based on the method of Bergmann et al. [1998] and used to generate synthetic GPR waveforms with a central source frequency of $250 \mathrm{MHz}$. Grid spacing of $2 \mathrm{~cm}$ was used for both the horizontal and vertical directions, and the time step of $0.075 \mathrm{~ns}$ used was. Parameters describing the electrical properties that are needed for simulation are also given in Table 1. (Note that the electrical conductivity must be specified for the finite difference approach and is also a function of water saturation; see Kowalsky et al. [2004b] for details.) The travel time measurements were obtained by picking the first-break arrival times from the synthetic waveforms and then adding measurement noise (zero-mean random deviates with standard deviation of 0.25 ns).

For emphasis, we note again that the GPR travel times used as synthetic data for inversion were calculated from the simulated full waveforms, which reflect complex EM wave propagation effects, such as ray curving; that is, the synthetic travel time data were not generated using the straight-ray approximation. However, to simulate GPR travel times during inversion, the straight ray approximation (10) is used because of its computational efficiency. In some cases this approximation can lead to systematic errors, which is discussed in Section 3.1.1.

The simulated water saturation profiles for two times (pre-injection and 18 hours after onset of injection) are shown in Figures $3 \mathrm{a}$ and $3 \mathrm{~b}$. In addition, the corresponding GPR 
waveforms recorded for one selected transmitting antenna are shown in Figures $3 \mathrm{c}$ and $3 \mathrm{~d}$ along with the travel times that were picked from the waveforms. Note the longer travel times resulting from the increased water saturation in the vicinity of the injection point.

\subsubsection{GPR travel time considerations}

For this uniform soil model, a systematic error (bias) in the simulated GPR straightray travel times occurs and must be accounted for to obtain good soil hydraulic parameter estimates. Figure 4 shows how error in the straight-ray travel times is related to the injection time and the distance that the straight-ray passes above or below the injection point (the errors were calculated relative to the travel times picked from waveforms simulated using the finite difference method, as discussed above). At early times, after the onset of injection but before the injected water spreads appreciably, the injected plume of water serves as a low velocity inclusion (increased water saturation results in decreased EM velocity) and causes a sharp contrast in the EM velocity. When the travel path of the earliest arriving energy is curved around the low-velocity inclusion, using the straight-ray approximation results in the inclusion appearing drier than it is in reality. While in this case the magnitude of the travel time error is small and on the order of the measurement noise (standard deviation of $0.25 \mathrm{~ns}$ ), it is a systematic rather than random error and thus introduces a bias, which significantly affects the accuracy of the soil hydraulic parameter estimates obtained through inversion.

The mean and standard deviation of the errors in the straight-ray arrival times for all post-injection surveys are $0.088 \mathrm{~ns}$ and $0.093 \mathrm{~ns}$, respectively. (The corresponding values for the pre-injection survey are much lower: 0.014 ns and 0.011 ns.) To partially 
compensate for the bias in the GPR travel times simulated using the straight-ray approximation at early post-injection times, we include the post-injection shift in the arrival times $\left(T_{\text {shift }}\right)$ as an unknown parameter to be estimated through inversion.

\subsubsection{Inversion results}

Using the time-lapse GPR travel time and borehole NP measurements described above, we test the approach for two different sets of unknown parameters. In Case 1, the vertical component of the log permeability $\left(k_{v}\right)$, the anisotropy ratio $\left(k_{v} / k_{h}\right)$, the porosity $(\phi)$, and the parameter $T_{\text {shift }}$ are estimated. In Case 2, two parameters of the relative permeability and capillary pressure functions, namely $m$ and $\log 1 / \alpha$, are estimated, along with the vertical component of the log permeability, the anisotropy ratio, and the parameter $T_{\text {shift }}$ In addition, we investigate various scenarios of uncertainty in the petrophysical function: (a) the petrophysical function is known accurately; the assumed or measured solid component dielectric constant $\left(\kappa_{s}\right)$ in the petrophysical function is inaccurate (i.e., it contains an error of (b) $+20 \%$ and (c) $-20 \%$ ); and (d) the parameter $\kappa_{s}$ is estimated through inversion along with the remaining unknown parameters. For this example, we assume no prior information is available for the unknown parameters (i.e., the prior pdfs are uniform), yielding the objective function (13) with only the first term.

At first we assume that the petrophysical function parameter $\kappa_{S}$ is known accurately (Case 1a), giving reasonably accurate estimates of the hydraulic parameters (Table 2), although the anisotropy ratio is over-predicted. The difference between the predicted water saturation distribution and that of the true model at a single time is depicted in Figure 5, showing good overall agreement (maximum relative difference of $10 \%$ ) with a 
slight under-prediction of water saturation in the vicinity of the plume. The parameter $T_{\text {shift }}$ is estimated to be $0.125 \mathrm{~ns}$, which is similar to the expected average bias in the straight-ray approximation, as discussed above.

In practice, a small (or large) amount of error can be unintentionally introduced into the petrophysical function, for example, when a petrophysical function derived from laboratory scale measurements is employed at the field scale, or when an unconfirmed generic function is used at a given site. To examine the impact of realistic errors in the petrophysical parameters on inversion results, we intentionally use incorrect values for the parameter $\kappa_{S}$ (errors of $+/-20 \%$ of its true value of 4.5 ). For these two cases (Cases $1 \mathrm{~b}$ and 1c), the resulting errors in the hydraulic parameter estimates are substantially increased (Table 2), most notably: the porosity is over-predicted and under-predicted by almost $30 \%$, for Cases $1 \mathrm{~b}$ and $1 \mathrm{c}$, respectively; and the anisotropy ratio is over-predicted by $60 \%$ for Case 1c. As shown in Figure 5, the water saturation profile is over-estimated (by up to $65 \%$ ) and under-estimated (by up to $30 \%$ ) for Cases $1 \mathrm{~b}$ and $1 \mathrm{c}$, respectively.

Note that the petrophysical function (8) depends not only on $\boldsymbol{K}_{\mathrm{s}}$ but also on porosity, which was estimated through inversion. The erroneous values of $\kappa_{\mathrm{s}}$ assumed for Cases $1 \mathrm{~b}$ and $1 \mathrm{c}$ and the corresponding inaccurate porosity estimates lead to highly inaccurate petrophysical functions (Figure 6).

Because errors in the petrophysical function can adversely affect hydraulic parameters estimates, our inversion methodology allows for such errors to be partially compensated by allowing one or more of the petrophysical parameters to be unknown $\left(\mathbf{a}_{G P R}\right)$ and jointly estimated with the remaining soil hydraulic parameters $\left(\mathbf{a}_{h}\right)$. For Case $1 \mathrm{~d}$, the parameter $\kappa_{S}$ is considered unknown and is estimated along with the remaining 
soil hydraulic parameters, which are estimated more accurately overall than for the previous cases (e.g., the error in the porosity estimate is reduced to $5 \%$ ). Consequently, the saturation profile is better predicted, to similar accuracy as for the case in which the parameter $\kappa_{s}$ was error free (Case 1a).

In Cases 2a-d we include in the estimation procedure two parameters of the capillary pressure and water retention functions-namely $m$ and $\log 1 / \alpha-$ and we again consider several cases of uncertainty in the petrophysical function. Considering Table 2 (and Figure 5) the following observations can be made: (1) that knowing the parameter $\kappa_{s}$ accurately allows for reasonable estimates of the soil hydraulic parameters and good predictions of the water profile (Case 2a); (2) the presence of error in the petrophysical function adversely affects estimates of the soil hydraulic parameters and of the predicted water saturation profiles (Cases $2 \mathrm{~b}$ and $2 \mathrm{c}$ ); and (3) adverse effects on hydraulic parameter estimates due to uncertainty in the parameter $\kappa_{S}$ are minimized when $\kappa_{S}$ is jointly estimated with the remaining hydraulic parameters (Case 2d).

For reference, the capillary pressure and relative permeability functions obtained for Cases 1 and 2 are shown in Figure 7. Note that the parameters of these functions were assumed to be known in Case 1, whereas two parameters were estimated in Case 2 (see Table 2).

Note that there is relatively little error in the petrophysical functions for Cases $2 b$ and 2c, relative to those for Cases $1 \mathrm{~b}$ and $1 \mathrm{c}$; this is because in Case 2 the correct porosity value is assumed, leaving only inaccuracy in $\kappa_{\mathrm{S}}$ to affect the petrophysical function (Figure 6). However, as was shown above, the small inaccuracies in $\kappa_{\mathrm{s}}$ were enough to 
cause large errors in the hydraulic parameters. But, joint estimation of $\kappa_{S}$ allowed for such inaccuracies to be largely overcome.

\subsection{Model with heterogeneous permeability}

The model explored in this example is identical to the one explored in Section 3.1, except that the log permeability considered at present is spatially heterogeneous (Figure 8a), having been generated using sequential simulation [Deutsch and Journel, 1992] with an anisotropic spherical semivariogram (Table 1). The remaining soil hydraulic parameters are modeled as spatially uniform. Synthetic data sets were obtained in the same fashion as in the previous example, except that the survey times of $12,24,36$, and 48 hours after injection are used, in addition to the pre-injection survey. Measurement noise was added to the synthetic NP and GPR data sets in the same manner as for the previous example.

We choose to estimate two vertical columns of pilot point (see Figure 8a), since the correlation length scale of heterogeneity in the horizontal direction is much longer than in the vertical direction. Computational considerations also affected this decision: while the use of more pilot points potentially better resolves lateral heterogeneity, the computation time required for inversion increases with the number of unknowns, which is a concern with three-dimensional models (such as is considered in Section 4). In total, 17 unknowns are estimated, namely, the uniform soil hydraulic parameters $\phi$ and $\log k_{v}, 14$ pilot point permeability values $\xi_{p p}$, and the petrophysical parameter $\kappa_{s}$. 
Recall that the entire permeability field is generated conditional to the permeability values at the pilot point locations, such that estimating the optimal pilot point values is tantamount to determining the optimal permeability distribution of the entire model.

The total flux at the surface is assumed to be known, as are the variance of the permeability field and the parameters of the log permeability semivariogram, the permeability anisotropy ratio $\left(k_{h}=4 k_{v}\right)$, and remaining soil hydraulic parameters. Note that the purpose of the examples presented here is not to design the optimal injection experiment, but rather to demonstrate the merit of the joint inversion approach.

\subsubsection{GPR travel time considerations}

In the previous example (Section 3.1), which utilized a uniform soil model, it was necessary to account for systematic error in the travel times results from the straight-ray approximation. However, in the present example, which contains a heterogeneous permeability distribution, there is minimal systematic error in the simulated straight-ray travel times. Because the injected water is dispersed and distributed more heterogeneously, corresponding to an increased "randomness" in the EM velocity field (as compared to the elliptically shaped plume in the previous example), the true ray paths no longer bend in a highly focused fashion around the injected water plume, making estimation of the parameter $T_{\text {shift }}$ unnecessary.

For comparison with the previous synthetic example (for data simulated at 18 hours after onset of injection), the mean and standard deviation of the errors in the straight-ray arrival times for the post-injection surveys, relative to the travel times picked from waveforms simulated using the finite difference technique, are $0.055 \mathrm{~ns}$ and $0.20 \mathrm{~ns}$, 
respectively. The corresponding values of the pre-injection survey are $-0.020 \mathrm{~ns}$ and 0.043 ns.

\subsubsection{Inversion results}

Using the time-lapse GPR travel time and NP measurements simulated for the heterogeneous model, we test the approach for the case in which the soil hydraulic parameters and the petrophysical parameter $\kappa_{s}$ are unknown, as described above. We assume no prior information is available for the unknown parameters, except for parameters of the log permeability semivariogram function (including the variance), yielding the objective function (13) with the first and second term. We performed 20 inversion realizations, each with a different realization of the initial permeability field, resulting in 20 equally plausible sets of parameters.

The estimated log permeability distributions compare well with that of the true model (as an example, one inversion realization is shown in Figure 8b). The mean of the multiple realizations is smooth, capturing the true model within the error bounds (see Figures $8 \mathrm{c}$ and $8 \mathrm{~d}$ ). Note that while the mean of the permeability realizations is smooth, the permeability fields estimated for each inversion realization reflect, on average, the specified spatial correlation model. Thus, the multiple permeability realizations could be used to predict flow phenomena, for example, the pdf of breakthrough time of the injected water reaching a control plane.

The predicted water saturation profiles, on average, match that of the true model (Figure 9). The peaks in water saturation near 1 and 1.5 meters depth are slightly underpredicted, especially for the earlier time shown (12 hours after the onset of injection). 
However, in all cases the peaks fall within the uncertainty bounds of the predicted profiles (Figures 9c and 9f).

The average of the predicted petrophyiscal functions, based on the estimated values of $\varphi$ and $\kappa_{s}$, is nearly identical to that of the true model (Figure 9).

\section{Application to field data from DOE Hanford site}

An application of the joint inversion method to a field data set is given in this section. The purpose is not to develop an optimal hydrological model for the field site considered, but rather to demonstrate the method in the context of a three-dimensional setting with actual field data and to demonstrate the potential benefit that GPR measurements offer for estimating soil hydraulic parameters.

\subsection{Description of site and experiment}

At the U.S. Department of Energy Hanford site, in Washington, vast quantities of highly radioactive waste and other toxic fluids have leaked into the vadose zone [e.g., Sisson and Lu, 1984; Gee and Ward, 2001; Hunt and Gee, 2002] and have necessitated the development of methods for monitoring and ultimately controlling the spread of contamination. Here we consider the Hanford 200 East Area field site (also known as the "Sisson and Lu site"), which has been the subject of a number of experiments [Sisson and Lu, 1984; Fayer et al. 1993; Fayer et al. 1995; Gee and Ward, 2001, 2002], and for which laboratory investigations of soil properties have been reported [Freeman, 2001; Last and Caldwell, 2001; Last et al., 2001; Schaap et al., 2003] and modeling studies performed 
[Smoot and Lu 1994; Smoot and Williams 1996; Rockhold et al. 1999; Zhang et al., 2004].

The infiltration experiment we consider here began in May of 2000 and consisted of 5 injections of water over a period of one month. Each injection of approximately $4000 \mathrm{~L}$ of water lasted between 4 and 6.75 hours. During the experiment, extensive NP measurements [Ward et al., 2000] and other geophysical data sets, including crossborehole GPR [Majer et al., 2000] and electrical resistance tomography (ERT) measurements [Ramirez et al., 2001], were collected. The schedule for the injections and the surveys are depicted in Figure 11. Baseline surveys for both the GPR and NP measurements were collected before injection, and these are assumed to reflect steadystate conditions. The NP surveys were typically conducted on the day following each injection, whereas the GPR surveys were collected sporadically.

The locations of the measurement access wells are shown in Figure 12. The dense NP measurements that were collected at an interval of $30.5 \mathrm{~cm}$ allow for construction of three-dimensional data sets through interpolation [e.g., Ward et al., 2000]. However, in this example the data collected in only 2 wells (see Figure 12) and at three survey times (NP-Pre, NP-1, NP-2 in Figure 11) are used for inversion, as are the GPR data for only two survey times (GPR-Pre and GPR-1). The dense NP data derived from all NP wells are used only to test the distributions predicted with the calibrated models at the time for which survey NP-3 was collected (corresponding to 15 days after the initial injection).

Figure 13a shows the distribution of water content derived from the dense NP data cube (for NP data collected in all 32 wells at one survey conducted 15 hours after the initial injection of water). The locations of the wells in which cross-borehole GPR 
measurements were collected are indicated in Figure 13b, as are the straight-ray paths for the GPR measurements used in this example (they represent a small subset selected from the available GPR measurements).

\subsection{Model with heterogeneous permeability}

We focus on a subset of the study area (the nodes of the hydrological model are indicated in Figure 12). The model domain is approximately $12 \mathrm{~m}$ in both horizontal directions, and $14 \mathrm{~m}$ in depth. The grid spacing ranges between 0.5 and $1.25 \mathrm{~m}$ in the horizontal directions, and equals $0.305 \mathrm{~m}$ in the vertical direction to allow for small-scale variability and to coincide with the vertical spacing of the NP measurements. We increased the vertical grid spacing of the bottom layers, since the water content in this region remains constant throughout the injection experiment. All elements in the top layer of the model are connected to one grid block, at which a small flux of water is applied to represent surface conditions. A free drainage boundary is implemented at the bottom of the model domain, as are no-flow boundaries at the four vertical sides. For the injection source, a time-dependent mass flow rate is specified at one grid point according to the schedule depicted in Figure 11. Since the actual time-varying flow rates are unknown (i.e., suspected to vary from the average values measured during the experiment), they are estimated with the remaining unknown parameters.

Based on geostatistical analyses of permeability measurements, an anisotropic spherical semivariogram was chosen to model the log permeability. Various parameters that are either assumed or estimated in the present example are listed in Table 3. 


\subsubsection{Inversion results}

Using the two GPR travel time surveys (GPR-Pre and GPR-1) and a small subset of the available NP measurements ( 2 wells for surveys NP-Pre, NP-1, and NP-2), we test the approach for estimating the unknown parameters listed in Table 3, which include the petrophysical parameter $\kappa_{s}$, the porosity, the mean log permeability, the log permeability modifier values at 16 pilot point locations, and a factor by which the reported flow rates at the injection point are multiplied. As before, we assume that no prior information is available for the unknown parameters, except for the estimated parameters of the $\log$ permeability semivariogram function, yielding the objective function (13) with the first and second terms.

Using both the GPR and the limited NP data sets, we performed multiple inversion realizations using a simulation duration that includes the first two injections in the field experiment and up to the time of the second GPR survey (GPR-1). The results are summarized in Table 3.

Water saturation distributions were simulated for the multiple three-dimensional models obtained through inversion for a duration lasting beyond the third water injection and up to the NP survey NP-3. The simulated water saturation distributions were then converted to water content (using the corresponding porosity estimates), so that the predictions could be compared to the three-dimensional water content data sets (obtained through interpolation of from the dense NP data set) for the same time.

In Figure 14, two-dimensional slices (along the line labeled AB in Figure 12) of the dense NP data set (Figure 14a) are compared to slices of the predicted water content distributions (for a single inversion realization) for two different cases of inversion. The 
first case (Figure 14b) includes inversion with only the limited NP data sets (i.e., no GPR measurements were used). The second case (Figure 14c) demonstrates the relative gain in this case of including measurements from two GPR surveys in the inversion. While the overall the trends are similar for both cases, inclusion of GPR measurements allows for the various peaks in water content occurring below the injection point to be captured somewhat better.

To better illustrate this point, vertical profiles (one-dimensional) of predicted and measured water content at a location near the injection well are given in Figure 15 for the same cases. In this figure, the mean of 5 inversion realizations is shown, as are the prediction uncertainty bounds. The parameters that were estimated for both cases are listed in Table 3.

It is worth emphasizing that while NP measurements were collected in 27 wells to obtain the dense NP data sets at eight times, only a limited subset of NP measurements at each time are actually used for inversion (see Figures 11 and 12); however, all NP data were used to test the inversion predictions.

\section{Conclusions}

A method was described for estimating field-scale soil hydraulic parameters and parameters of the petrophysical function using time-lapse multiple-offset cross-borehole GPR travel times and other hydrological measurements, such as water content measurements inferred from neutron probe logs. This research builds upon previous work in order to accommodate uncertainty in the petrophysical function and to increase the 
flexibility of GPR measurement configurations that may be considered, and consequently increase the resolution at which soil hydraulic parameters may be estimated.

The method was applied to two synthetic examples, which consisted of a model with uniform soil hydraulic parameters and a model with heterogeneous permeability. Potential errors in the petrophysical function were observed to significantly affect the soil hydraulic parameter estimates, but inclusion of a petrophysical parameter in the joint inversion procedure allowed for improved estimates of the soil hydraulic parameters.

The importance of accounting for errors in the forward model used for simulating GPR measurements was also addressed. Using the straight-ray approximation to simulate GPR travel times introduces bias in some cases-the travel time bias was spatially dependent and time dependent, showing over-prediction near the edges of the water plume at early times in the injection experiment. To compensate for this bias, an additional correction parameter was estimated during inversion. In heterogeneous models, the bias was minimal, making estimation of the correction parameter unnecessary.

Finally, the method was applied to the U.S. Department of Energy (DOE) Hanford field site in Washington, where time-lapse GPR and NP data sets were collected. Compared to predictions made through inversion of a limited NP data set, inclusion of GPR data in the inversion procedure allowed for soil hydraulic parameter estimates that gave improved predictions of water saturation. We conclude that the approach can provide in a minimally invasive manner accurate estimates of field-scale soil hydraulic parameters. 
Related ongoing research includes: (1) implementing GPR forward modeling capabilities for additional measurement types (e.g., cross-borehole amplitude and surface reflection data); (2) incorporating capabilities for joint inversion with additional geophysical data types, such as from seismic and electrical methods; (3) accounting for spatial variations of the petrophysical function and its dependence on temperature; and (4) exploring the potential of estimating parameters of the spatial correlation functions within the procedure. Alternative joint inversion methodologies and different descriptions of geological heterogeneity as applied to the Hanford site experiment will also be explored in the future.

\section{Acknowledgments}

This work was supported by U.S. Dept. of Energy under Contract No. DE-AC0376SF00098. 


\section{References}

Alharthi, A., and J. Lange (1987), Soil water saturation: Dielectric determination, Water Resour. Res., 23, 591-595, 1987.

Alumbaugh D., P. Y. Chang, L. Paprocki, J. R. Brainard, R. J. Glass, and C. A. Rautman (2002), Estimating moisture contents in the vadose zone using cross-borehole ground penetrating radar: A study of accuracy and repeatability, Water Resour. Res., 38 (12), 1309, doi:10.1029/2001WR000754.

Annan, P. (2005), GPR Methods for Hydrogeological Studies, Ch. 7 in: Hydrogeophysics, edited by Y. Rubin and S. S. Hubbard S. S., Springer, Dordrecht, The Netherlands, $532 \mathrm{pp}$.

Ansoult, M., L. W. DeBacker, and M. Declrercq (1984), Statistical relationship between apparent dielectric constant and water content in porous media, J. of the Soil Science Society of America, 48, 47-50.

Archie, G. E. (1942), The electrical resistivity log as an aid in determining some reservoir characteristics, Trans. Amer. Inst. Mineral. Mat., 146, 54-62.

Bergmann, T., J.O.A. Robertsson, K. Holliger (1998), Finite-difference modeling of electromagnetic wave propagation in dispersive and attenuating media, Geophysics, 63(3), 856-867.

Binley, A., P. Winship, R. Middleton, M. Pokar, and J. West (2001), High-resolution characterization of vadose zone dynamics using cross-borehole radar. Water Resour. Res., 37(11), 2639-2652. 
Binley, A., G. Cassiani, R. Middleton, and P. Winship (2002), Vadose zone flow model parameterization using cross-borehole radar and resistivity imaging, J. of Hydrol., 267, 147-159.

Birchak, J. R., L. G. Gardner, J. W. Hipp, and J. M. Victor (1974), High dielectric constant microwave probes for sensing soil moisture, Proceedings of IEEE, 62 (1), 93-98.

Bregman, N. D., R. C. Bailey, and C. H. Chapman (1989), Crosshole seismic tomography, Geophysics, 54, 200-215.

Cai, J., and G. A. McMechan (1995), Ray-based synthesis of bistatic ground penetrating radar profiles, Geophysics, 60, 87-96.

Casper, D. A., and K.-J. S. Kung (1996), Simulation of ground-penetrating radar waves in a 2-D soil model, Geophysics, 61, 1034-49.

Chan, C. Y., and R. J. Knight (1999), Determining water content and saturation from dielectric measurements in layered materials, Water Resour. Res., 35(1), 85-94, 10.1029/1998WR900039.

Daniels, D. J. (1996), Surface Penetrating Radar, Institute of Electrical Engineers, London, United Kingdom.

Davis, J. L., and A. P. Annan (1989), Ground-penetrating radar for high-resolution mapping of soil and rock stratigraphy, Geophysical Prospecting, 37, 531-551.

Day-Lewis, F. D., and J. W. Jr., Lane (2004), Assessing the resolution-dependent utility of tomograms for geostatistics, Geophys. Res. Lett., 31(7), L07503. 10.1029/2004GL019617. 
Deutsch, C. V., and A.G. Journel (1992), GSLIB: Geostatistical Software Library and User's Guide, New York, Oxford University Press.

Dobson, M. C., F. T. Ulaby, M. T. Hallikainen, and M. A. El-Rayes (1985), Microwave dielectric behavior of wet soils - part II: dielectric mixing models, IEEE Transactions on Geoscience and Remote Sensing, GE-32(1), 35-46.

Eppstein, M. J., and D. E. Dougherty (1998), Efficient three-dimensional data inversion: Soil characterization and moisture monitoring from cross-well ground-penetrating radar at a Vermont test site, Water Resour. Res., 34(8):1889-1900.

Fares, A., P. Buss, M. Dalton, A. I. El-Kadi, and L. R. Parsons (2004), Dual Field Calibration of Capacitance and Neutron Soil Water Sensors in a Shrinking-Swelling Clay Soil, Vadose Zone J., 3, 1390-1399.

Fayer, M. J., J. B. Sisson, W. A. Jordan, A. H. Lu, and P. R. Heller (1993), Subsurface injection of radioactive tracers: Field experiment for model validation testing. NUREG/CR-5996, U. S. Nuclear Regulatory Commission, Washington, D. C.

Fayer, M. J., R. E. Lewis, R. E. Engleman, A. L. Pearson, C. J. Murray, J. L. Smoot, R. R. Randall, W. H. Wegener, and A. H. Lu (1995), Re-evaluation of a subsurface injection experiment for testing of flow and transport models, Report PNL-10860, Pacific Northwest National Laboratory, Richland, Washington.

Finsterle, S. (1999), iTOUGH2 User's Guide, Report LBNL-40040, Lawrence Berkeley National Laboratory, Berkeley, CA.

Freeman, E. J., R. Khaleel, and P. R. Heller (2001), A Catalog of Vadose Zone Hydraulic Properties for the Hanford Site, Report PNNL-13672, Pacific Northwest National Laboratory, Richland, WA. 
Friedman, S. P. (1998), A saturation degree-dependent composite spheres model for describing the effective dielectric constant of unsaturated porous media, Water Resour. Res., 34(11), 2949-2961.

Gee, G. W., and A. L. Ward (2001), Vadose zone transport field study, Report PNNL13982, Pacific Northwest National Laboratory, Richland, WA.

Gomez-Hernandez, J. J., A. Sahuquillo, J. E. Capilla (1997), Stochastic simulation of transmissivity fields conditional to both tranmissivity and piezometric data -1 , Theory. J of Hydrol, 203, 162-174.

Hubbard, S. S., Y. Rubin, and E. Majer (1997), Ground-penetrating-radar assisted saturation and permeability estimation in bimodal systems, Water Resour. Res, 33, 971-990.

Huisman, J. A., S. S. Hubbard, J. D. Redman, and A. P. Annan, Measuring soil water content with ground penetrating radar: a review, Vadose Zone J., 2, 476-91.

Hunt, A. G. and G. W. Gee (2002), Water-Retention of Fractal Soil Models Using Continuum Percolation Theory: Tests of Hanford Site Soils, Vadose Zone J., 1, 252260

Hyndman, D. W., J. M. Harris, and S. M. Gorelick (1994), Coupled seismic and tracer test inversion for aquifer property characterization, Water Resour. Res., 30(7), 19651977.

Hyndman, D. W., S. M. Gorelick (1996), Estimating lithological and transport properties in three dimensions using seismic and tracer data, the Kesterson aquifer, Water Resour. Res., 32(9), 2659-2670. 
Jacobsen, O. H., P. Schjonning (1993), A laboratory calibration of time domain reflectometry for soil water measurement including effects of bulk soil density and texture, J. Hydrology, 151, 147-157.

Jury, W. A., D. Russo, G. Sposito, and H. Elabd (1987), The spatial variability of water and solute transport properties in unsaturated soil: I. Analysis of property variation and spatial structure with statistical models. Hilgardia, 55, 1-32.

Kowalsky, M. B., S. A. Finsterle, and Y. Rubin (2004a), Estimating flow parameter distributions using ground-penetrating radar and hydrological measurements during transient flow in the vadose zone, Advances in Water Resour., 27(6), 583-599.

Kowalsky, M. B., Y. Rubin, and P. Dietrich (2004b), The use of ground-penetrating radar for characterizing sediments under transient flow conditions, in Aquifer characterization, SEPM Special Publication 80, edited by J.S. Bridge and D. W. Hyndman, pp. 107-127.

Kunz, K. S., and R. J. Luebbers (1993), The finite difference time domain method for electromagnetics, CRC Press, Boca Raton, FL.

Lambot, S., M. Antoine, I. van den Bosch, E. C. Slob, and M. Vanclooster (2004), Electromagnetic Inversion of GPR Signals and Subsequent Hydrodynamic Inversion to Estimate Effective Vadose Zone Hydraulic Properties, Vadose Zone J., 3, 10721081.

Last, G. V., and T. G. Caldwell (2001), Core sampling in Support of the Vadose Zone Transport Field Study, Report PNNL-13454, Pacific Northwest National Laboratory, Richland, WA. 
Last, G. V., T. G. Caldwell, and A.T. Owen (2001), Sampling of boreholes WL-3A through -12 in support of the vadose zone transport field study, Report PNNL-13631, Pacific Northwest National Laboratory, Richland, WA.

Lesmes, D. P., and S. P. Friedman (2005), Relationships between the electrical and hydrogeological properties of rocks and soils, Ch. 4 in : Hydrogeophysics, edited by Y. Rubin and S. S. Hubbard, Springer, Dordrecht, The Netherlands, 532 pp.

Levenberg, K. (1944), A Method for the Solution of Certain Problems in Least Squares, Quart. Appl. Math., 2, 164-168.

Linde, N., S. Finsterle, and S. S. Hubbard (2005), Inversion of tracer test data using tomographic constraints, submitted to WRR.

de Loor, G. P. (1964), Dielectric properties of heterogeneous mixtures. Appl. Sci. Res., B3, 479-482.

Majer, E. L., J. E. Peterson, K. H. Williams, T. M. Daley, and G. Gee (2000), High Resolution of Vadose Zone Transport Using Crosswell Radar and Seismic Methods, Report PNNL-13791, Pacific Northwest National Laboratory, Richland, WA.

Martinez, A., and A. P. Byrnes (2001), Modeling Dielectric-constant values of Geologic Materials: An aid to Ground-Penetrating Radar Data Collection and Interpretation, Current Research in Earth Sciences, Bulletin 247, part 1, 1-16.

Marquardt, D. (1963), An algorithm for least squares estimation of nonlinear parameters. SIAM J. Appl. Math., 11, 431-441.

McLaughlin, D., and L. R. Townley (1996), A reassessment of the groundwater inverse problem. Water Resour. Res., 32(5), 1131-1161. 
Moysey, S., and R. Knight (2004), Modeling the field-scale relationship between dielectric constant and water content in heterogeneous system, Water Resour. Res., 40, W03510, doi:10.1029/2003WR002589.

Or, D., and J. M. Wraith (1999), Temperature effects on soil bulk dielectric permittivity measured by time domain reflectometry: A physical model, Water Resour. Res., 35(2), 371-383.

Persson, M., B. Sivakumar, R. Berndtsson, O. H. Jacobsen, P. Schjonning (2002), Predicting the dielectric constant-water content relationship using artificial neural networks, Soil Sci. Soc. Am. J., 66, 1424-1429.

Peterson, J. E., B. N. P. Paulsson, and T. V. McEvilly (1985), Applications of algebraic reconstruction techniques to crosshole seismic data, Geophysics, 50, 1566-1580.

Peterson, J.E. (2001), Pre-inversion Corrections and Analysis of Radar Tomographic Data, Journal of Environmental and Engineering Geophysics, 6(1), pp. 1-18.

Philip, J. R. (1991), Horizontal Redistribution with capillary hysteresis, Water Resour Res, 27(7), 1459-1469.

Pruess, K., C. Oldenburg, G. Moridis (1999), TOUGH2 User's Guide, Version 2.0, Report LBNL-43134, Lawrence Berkeley National Laboratory, Berkeley, CA.

Pruess, K., S. Yabusaki, C. Steefel, and P. Lichtner (2001), Fluid Flow, Heat Transfer, and Solute Transport at Nuclear Waste Storage Tanks in the Hanford Vadose Zone, Vadose Zone J., 1, 69-88.

RamaRao, B.S., G. de Marsily, M. G. Marietta (1995), Pilot Point Methodology for Automated Calibration of an Ensemble of Conditionally Simulated Transmissivity 
Fields I: Theory and Computational Experiments. Water Resour. Res., 31(3), 475493.

Ramirez, A., W. Daily, A. Binley, and G. W. Gee (2001), Final Report, FY 2001, 200 East Vadose Test Site Hanford, Washington, Electrical Resistance Tomography, Report PNNL-13794, Pacific Northwest National Laboratory, Richland, WA.

Robinson D. A., S. B. Jones S. B., J. M. Wraith, D. Or, and S. P. Friedman (2003), Advances in dielectric and electrical conductivity measurement using time domain reflectometry: simultaneous measurement of water content and bulk electrical conductivity in soils and porous media, Vadose Zone J., 2, 444-475

Robinson, D. A., M. G. Schaap, D. Or, and S. B. Jones (2005), On the effective measurement frequency of time domain reflectometry in dispersive and nonconductive dielectric materials, Water Resour. Res., 41, W02007, doi:10.1029/2004WR003816.

Rockhold, M. L., C. J. Murray, and M. J. Fayer (1999), Conditional simulation and upscaling of soil properties, pp. 1391-1402, In Proceedings of the International Workshop on Characterization and Measurement of the Hydraulic Properties of Unsaturated Porous Media, edited by M. Th, van Genuchten, F. J. Leij, and L. Wu., University of California, Riverside.

Roth, K. R., R. Schulin, H. Fluhler, and W. Attinger (1990), Calibration of time domain reflectometry for water content measurement using a composite dielectric approach, Water Resour. Res., 26, 2267-2273.

Rubin, Y., Applied stochastic hydrogeology (2003), Oxford University Press, New York. 
Rucker, D. F. and T. P. A. Ferré (2004), Parameter Estimation for Soil Hydraulic Properties Using Zero-Offset Borehole Radar: Analytical Method, Soil Sci. Soc. Am. J., 68, 1560-1567.

Russo, D., M. Bouton (1992), Statistical analysis of spatial variability in unsaturated flow parameters, Water Resour. Res., 28, 1911-1925.

Schaap, M. G., P. J. Shouse, P. D. Meyer (2003), Laboratory Measurements of the Unsaturated Hydraulic Properties at the Vadose Zone Transport Field Study Site, Report PNNL-14284, Pacific Northwest National Laboratory, Richland, WA.

Sihvola, A. (1999), Electromagnetic mixing formulas and applications, IEEE Electromagnetic Waves Series 47, The Institute of Electrical Engineers, London, United Kingdom.

Sisson, J. B., A. H. Lu (1984), Field calibration of computer models for applications to buried liquid discharges: a status report, Tech. Rep. RHO-ST-46-P, Rockwell Hanford Operations, Richland, WA.

Smoot, J. L., and A. H. Lu (1994), Interpretation and modeling of a subsurface injection test, 200 East Area, Hanford, Washington, In Thirty-third Hanford Symposium on Health and the Environment. In-situ Remeditaion: Scientific Basis for Current and Future Technologies, edited by G.W. Gee and N. R. Wing, Richland, WA.

Smoot, J. L., and R. E. Williams (1996), A Geostatistical methodology to assess the accuracy of unsaturated flow models, NUREG/CR-6411, U. S. Nuclear Regulatory Commission, Washington, D. C.

Stewart, R. R. (1991), Exploration Seismic Tomography: Fundamentals, Society of Exploration Geophysicists, Course Notes Series, 3, 140 pp. 
Topp, G. C., J. L. Davis, and A. P. Annan (1980), Electromagnetic determination of soil water content: Measurements in coaxial transmission lines, Water Resour. Res., 16(3), 574-582.

van Genuchten, M. T. (1980), A closed-form equation for predicting the hydraulic conductivity of unsaturated soils, Soil Sci. Soc. Am. J., 44, 892-898.

Ward, A.L., T. G. Caldwell, and G. W. Gee (2000), Vadose Zone Transport Field Study: Soil Water Content Distributions by Neutron Moderation, Report PNNL-13795, Pacific Northwest National Laboratory, Richland, WA.

Ward, A.L., and G.W. Gee (2001), Vadose zone transport field study: FY 2002 Test Plan, Report PNNL-13857, Pacific Northwest National Laboratory, Richland, WA.

Yao, T., P. J. Wierenga, A. R. Graham, and S. P. Neuman (2004), Neutron Probe Calibration in a Vertically stratified Vadose Zone, Vadose Zone J., 3, 1400-1406.

Zhang, Z. F., A. L. Ward, and G. W. Gee (2004), A combined parameter scaling and inverse technique to upscale the unsaturated hydraulic parameters for heterogeneous soils, Water Resour. Res., 40, W08306, doi:10.1029/2003WR002925. 


\section{List of Figures}

Figure 1. Flow chart for joint inversion of geophysical and hydrological measurements using framework of iTOUGH2 [Finsterle, 1999].

Figure 2. Model geometry for synthetic examples: (a) injection point and neutron probe measurement locations; (b) straight-ray paths and antenna locations.

Figure 3. Simulated saturation profiles (a) before injection (steady state) and (b) 18 hours after onset of injection for model with uniform soil parameters. A single transmitting antenna position $\left(T_{5}\right)$ is labeled with a square (there are 7 transmitting antenna positions in all, as shown in Figure 2), which the receiving antenna positions $\left(\mathrm{R}_{\mathrm{x}}\right)$ are labeled with triangles. Simulated waveforms are shown in (c) and (d), corresponding to the simulation times for (a) and (b), respectively. Circles denote the arrival times (before measurement noise is added).

Figure 4. Difference between straight-ray travel times $\left(T_{\mathrm{SR}}\right)$ and the travel times calculated using a finite difference method $\left(\mathrm{T}_{\mathrm{FD}}\right)$ versus vertical distance by which ray passes above or below injection point (for model with uniform soil parameters).

Figure 5. Predicted saturation profiles at 18 hours after onset of injection for Cases 1a-d (left) and Cases 2a-d (right) for example in Section 3.1. The profiles are vertical slices taken from the two-dimensional models at a horizontal distance of $2 \mathrm{~m}$.

Figure 6. Petrophysical functions for Case 1 (left) and Case 2 (right) of example in Section 3.1 .

Figure 7. Capillary pressure functions (left axis) and relative permeability function (right axis) for example in Section 3.1. For Case 1, the relative permeability function and the capillary pressure function are fixed to those of the true model (circles). For Case 2, the parameters $\log (1 / \alpha)$ and $m$ of the capillary pressure function and relative permeability functions are estimated through inversion.

Figure 8. (a) True log permeability distribution for model in Section 3.2, (b) single realization of estimated permeability field, (c) the ensemble mean of the predicted distributions, and (d) vertical cross section showing distribution for true model (solid line), mean of the predicted distributions (dashed line), and the uncertainty bounds for predicted distributions (dotted lines), defined as $+/-2$ standard deviations. The $\mathrm{x}$ symbols in (a) indicate pilot point locations used for inversion.

Figure 9. For heterogeneous model (Section 3.2), (a) the distribution of water saturation in the true model, (b) the ensemble mean of the predicted water distributions, and (c) vertical cross section of water saturation for true model (solid line), the average of the predicted distribution of water saturation (dashed line), and the uncertainty bounds (dotted lines) at 12 hours after the onset of water injection. The same cases described in (a)-(c) are shown in (d)-(f) at 24 hours after the onset of injection. 
Figure 10. Petrophysical functions for heterogeneous example in Section 3.2: true model (squares); ensemble mean of the estimated petrophysical functions (solid line); and uncertainty bounds (dashed lines), defined as $+/$ - two standard deviations.

Figure 11. Measurement schedule for injection experiment at Hanford site. NP and GPR data sets were collected before the first injection (NP-pre and GPR-Pre, respectively) and at later times (NP-1 to NP-7, and GPR-1 to GPR-7, respectively). A limited subset of NP data were used for inversion ( 2 wells indicated in Figure 12 at survey times NP-Pre, NP1, and NP-2). The GPR data sets used for inversion are GPR-Pre and GPR-1.

Figure 12. Measurement locations at the Hanford site and plan view of numerical grid used for hydrological modeling. Note that only 2 NP wells (solid circles) are used for inversion, while the remaining $30 \mathrm{NP}$ wells (open circles) are only used to test the inversion results.

Figure 13. Available data sets collected during injection experiment at the Hanford site: a) example of densely sampled NP data set (interpolated from NP wells, indicated by solid black vertical lines); b) straight ray paths that are formed by the 4 GPR wells are used for inversion.

Figure 14. Comparison of water content $(\theta)$ slice $A B$ (see Figure 12) from threedimensional model a) from dense NP data set, and predicted with single inversion realization using b) limited NP data set (using 2 wells at three times), and c) using the GPR data set (collected using 4 GPR wells at two survey times) and the limited NP data set.

Figure 15. Comparison of water content profile near injection point obtained from dense NP data set (circles) with the mean of the predicted water content profiles (solid line with dots) obtained through inversion of (a) limited NP data set (using 5 wells at three times) and (b) both the GPR data set and the limited NP data set. Note that while NP measurements were collected in 27 wells to obtain the dense NP data sets, only a limited subset of NP measurements are actually used for inversion (see Figure 12); however, all NP data are used to test the inversion predictions. The dashed lines around the mean of the predicted profiles indicate the estimation uncertainty ( $+/-2$ standard deviations). 


\section{List of Tables}

Table 1. Properties used for synthetic examples.

Table 2. Estimated parameters for synthetic model with uniform soil hydraulic parameters. The word "fixed" indicates that the true parameter value from the model is assumed to be known for that case; values in \{\} are the incorrect values used in inversion to test sensitivity to the error in $\kappa_{s}$; values in ( ) are the marginal standard deviations of the estimated parameter.

Table 3. Assigned and estimated parameters (not including pilot point log permeability modifier estimates) for application of method to Hanford field data. 
Table 1. Properties used for synthetic examples.

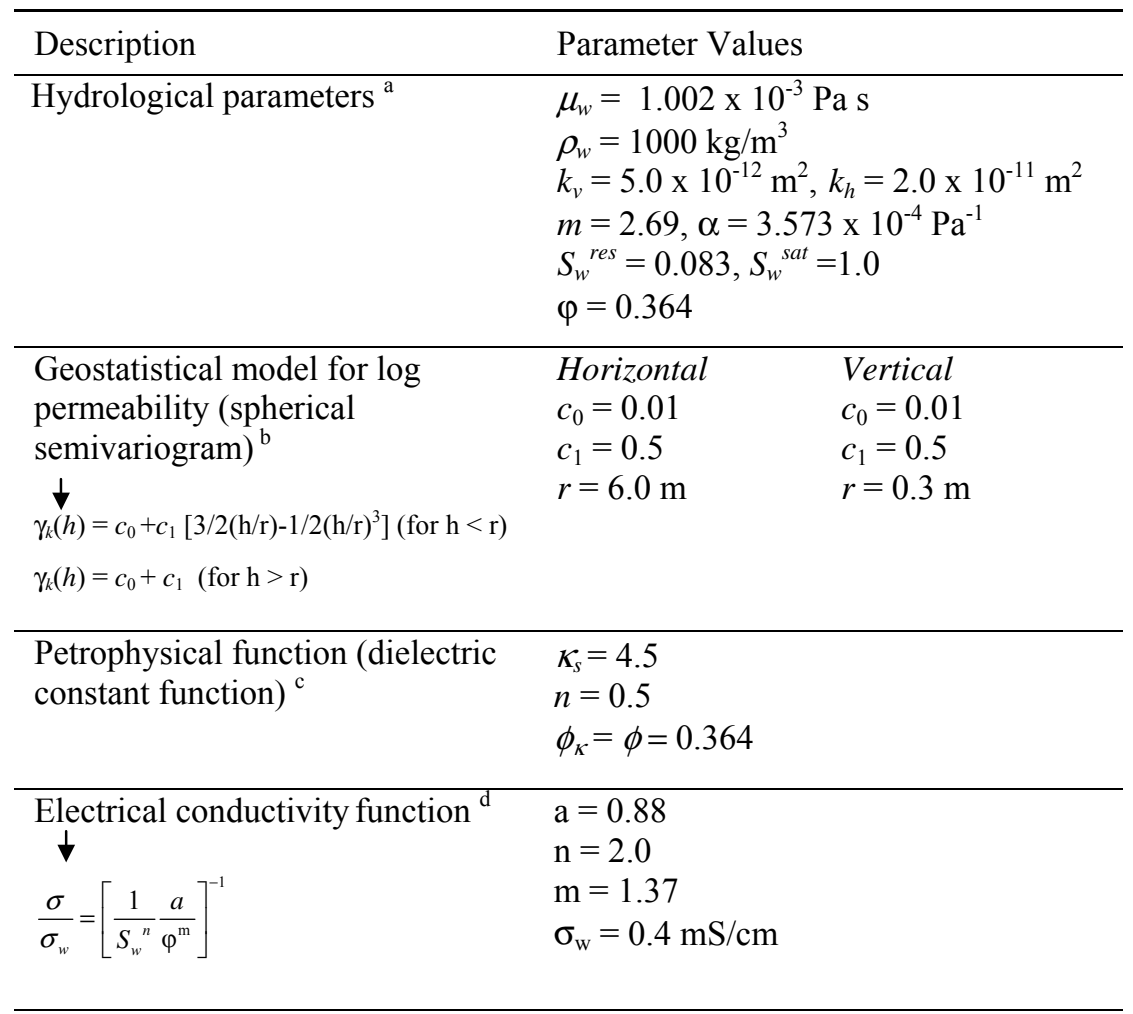

${ }^{a}$ Parameters defined in text; see description of (2) - (5).

${ }^{\mathrm{b}}$ For example in Section 3.2. $h$ is separation distance $(\mathrm{m}), c_{0}$ and $c_{1}$ are nugget and variance, respectively. The range is a measure of spatial persistence for the spherical semivariogram [Deutsch and Journel, 1992].

c Parameters defined in text; see description of (8).

${ }^{\mathrm{d}}$ Archie [1942]; also see Kowalsky et al. [2004b] for description. Used for generating synthetic waveforms with finite difference method; not used in calculating straight ray travel times with (10). 
Table 2. Estimated parameters for synthetic model with uniform soil hydraulic parameters. The word "fixed" indicates that the true parameter value from the model is assumed to be known for that case; values in \{\} are the incorrect values used in inversion to test sensitivity to the error in $\kappa_{s}$; values in ( ) are the marginal standard deviations of the estimated parameter.

\begin{tabular}{|c|c|c|c|c|c|c|c|}
\hline & $\kappa_{s}$ & $\begin{array}{c}\log k_{v} \\
{\left[k_{v}, \mathrm{~m}^{2}\right]}\end{array}$ & $k_{v} / k_{h}$ & $m$ & $\begin{array}{l}\log (1 / \alpha) \\
{\left[\alpha, \mathrm{Pa}^{-1}\right]}\end{array}$ & $\varphi$ & $\begin{array}{l}\mathrm{T}_{\text {shift }} \\
{[\mathrm{ns}]}\end{array}$ \\
\hline $\begin{array}{l}\text { True } \\
\text { model }\end{array}$ & 4.5 & -11.301 & 0.25 & 2.69 & 3.447 & 0.364 & N/A \\
\hline Case 1a & fixed & $\begin{array}{c}-11.270 \\
( \pm 0.022)\end{array}$ & $\begin{array}{c}0.3230 \\
( \pm 0.3 \mathrm{E}-3)\end{array}$ & fixed & fixed & $\begin{array}{c}0.384 \\
( \pm 0.006)\end{array}$ & $\begin{array}{c}0.125 \\
( \pm 0.03)\end{array}$ \\
\hline $1 \mathrm{~b}$ & $\{5.4\}$ & $\begin{array}{c}-10.679 \\
( \pm 0.019)\end{array}$ & $\begin{array}{c}0.216 \\
( \pm 0.014)\end{array}$ & fixed & fixed & $\begin{array}{c}0.467 \\
( \pm 0.005)\end{array}$ & $\begin{array}{c}0.055 \\
( \pm 0.033)\end{array}$ \\
\hline 1c & $\{3.6\}$ & $\begin{array}{c}-12.243 \\
( \pm 0.056)\end{array}$ & $\begin{array}{c}0.42 \\
( \pm 0.6 \mathrm{E}-3)\end{array}$ & fixed & fixed & $\begin{array}{c}0.262 \\
( \pm 0.009)\end{array}$ & $\begin{array}{c}0.26 \\
( \pm 0.04)\end{array}$ \\
\hline 1d & $\begin{array}{c}4.52 \\
( \pm 0.046)\end{array}$ & $\begin{array}{c}-11.262 \\
( \pm 0.043)\end{array}$ & $\begin{array}{c}0.325 \\
( \pm 0.26 \mathrm{E}-3)\end{array}$ & fixed & fixed & $\begin{array}{c}0.384 \\
( \pm 0.008)\end{array}$ & $\begin{array}{c}0.119 \\
( \pm 0.033)\end{array}$ \\
\hline Case 2a & fixed & $\begin{array}{l}-11.2308 \\
( \pm 0.051)\end{array}$ & $\begin{array}{c}0.252 \\
( \pm 0.007)\end{array}$ & $\begin{array}{c}2.57 \\
( \pm 0.063)\end{array}$ & $\begin{array}{c}3.38 \\
( \pm 0.04)\end{array}$ & fixed & $\begin{array}{c}0.0916 \\
( \pm 0.034)\end{array}$ \\
\hline $2 \mathbf{b}$ & $\{5.4\}$ & $\begin{array}{c}-11.550 \\
( \pm 0.046)\end{array}$ & $\begin{array}{c}0.167 \\
( \pm 0.014)\end{array}$ & $\begin{array}{c}4.495 \\
( \pm 0.261)\end{array}$ & $\begin{array}{c}3.77 \\
( \pm 0.04)\end{array}$ & fixed & $\begin{array}{c}-0.0216 \\
( \pm 0.038)\end{array}$ \\
\hline 2c & $\{3.6\}$ & $\begin{array}{c}-11.225 \\
( \pm 0.048)\end{array}$ & $\begin{array}{c}0.570 \\
( \pm 0.047)\end{array}$ & $\begin{array}{c}2.160 \\
( \pm 0.033)\end{array}$ & $\begin{array}{c}3.32 \\
( \pm 0.02)\end{array}$ & fixed & $\begin{array}{c}0.199 \\
( \pm 0.04)\end{array}$ \\
\hline 2d & $\begin{array}{c}4.496 \\
( \pm 0.042)\end{array}$ & $\begin{array}{c}-11.176 \\
( \pm 0.025)\end{array}$ & $\begin{array}{c}0.223 \\
( \pm 0.023)\end{array}$ & $\begin{array}{c}2.480 \\
( \pm 0.003)\end{array}$ & $\begin{array}{c}3.34 \\
( \pm 0.02)\end{array}$ & fixed & $\begin{array}{c}0.123 \\
( \pm 0.034)\end{array}$ \\
\hline
\end{tabular}


Table 3. Assigned and estimated parameters (not including pilot point log permeability modifier estimates) for application of method to Hanford field data.

\begin{tabular}{|c|c|c|c|}
\hline Description & Fixed parameter values & $\begin{array}{l}\text { Estimated } \\
\text { parameters } \\
\text { (NP data only) }\end{array}$ & $\begin{array}{l}\text { Estimated } \\
\text { parameters } \\
\text { (GPR+NP data) }\end{array}$ \\
\hline $\begin{array}{l}\text { Petrophysical function } \\
\text { parameters. See (8). }\end{array}$ & $\begin{array}{l}n=0.5 \\
\kappa_{w}=81 \\
\kappa_{a}=1\end{array}$ & Not estimated & $\begin{array}{l}\kappa_{s}=4.137 \\
( \pm 0.074)\end{array}$ \\
\hline $\begin{array}{l}\text { Flow modeling parameters } \\
\text { See }(2) \text { and }(3)^{\mathrm{a}} \text {. }\end{array}$ & $\begin{array}{l}\mu_{w}=1.002 \times 10^{-3} \mathrm{~Pa} \mathrm{~s} \\
\rho_{w}=1000 \mathrm{~kg} / \mathrm{m}^{3} \\
k_{v} / k_{h}=0.05\end{array}$ & $\begin{array}{l}\log \left[k_{v}\left(\mathrm{~m}^{2}\right)\right]= \\
-11.683( \pm 0.620) \\
\varphi=0.233 \\
( \pm 0.057)\end{array}$ & $\begin{array}{l}\log \left[k_{v}\left(\mathrm{~m}^{2}\right)\right]= \\
-11.928( \pm 0.243) \\
\varphi=0.189 \\
( \pm 0.030)\end{array}$ \\
\hline $\begin{array}{l}\text { Relative permeability and } \\
\text { capillary pressure } \\
\text { functions. } \\
\text { See }(4) \text { and }(5)^{\mathrm{a}} \text {. }\end{array}$ & $\begin{array}{l}S_{w}{ }^{\text {res }}=0.083 \\
S_{w}{ }^{\text {sat }}=1.0 \\
\mathrm{~m}=3.447 \\
\log \left[\alpha^{-1}(\mathrm{~Pa})\right]=3.45\end{array}$ & fixed & fixed \\
\hline $\begin{array}{l}\text { Geostatistical model for } \\
\text { log permeability (spherical } \\
\text { semivariogram) }\end{array}$ & $\begin{array}{l}\text { Horizontal } \\
c_{0}=0.0, c_{1}=0.269, r=20.0 \mathrm{~m} \\
\text { Vertical } \\
c_{0}=0.0, c_{1}=0.269, r=0.8 \mathrm{~m}\end{array}$ & fixed & fixed \\
\hline $\begin{array}{l}\text { Injection flow rate } \\
\text { (duration) }^{c}\end{array}$ & $\begin{array}{l}\mathrm{Q}_{1}=0.278 \times F \mathrm{~kg} / \mathrm{s}(4 \mathrm{~h}) \\
\mathrm{Q}_{2}=0.165 \times F \mathrm{~kg} / \mathrm{s}(6.75 \mathrm{~h}) \\
\mathrm{Q}_{3}=0.185 \mathrm{~kg} / \mathrm{s}(6 \mathrm{~h}) \\
\mathrm{Q}_{4}=0.185 \mathrm{~kg} / \mathrm{s}(6 \mathrm{~h}) \\
\mathrm{Q}_{5}=0.185 \mathrm{~kg} / \mathrm{s}(6 \mathrm{~h})\end{array}$ & $F=1.03( \pm 0.22)$ & $F=1.25( \pm 0.10)$ \\
\hline Boundary conditions & $\begin{array}{l}\text { Bottom: free drainage } \\
\text { Sides: zero flux } \\
\text { Top: total flux }=1.0 \mathrm{e}-4 \mathrm{~kg} / \mathrm{s}\end{array}$ & fixed & fixed \\
\hline
\end{tabular}

\footnotetext{
${ }^{\text {a }}$ Parameters defined in text.

${ }^{\mathrm{b}}$ As defined in Table 1.

${ }^{\mathrm{c}} \mathrm{F}$ is the factor by which the measured injection flow rate is multiplied.
} 


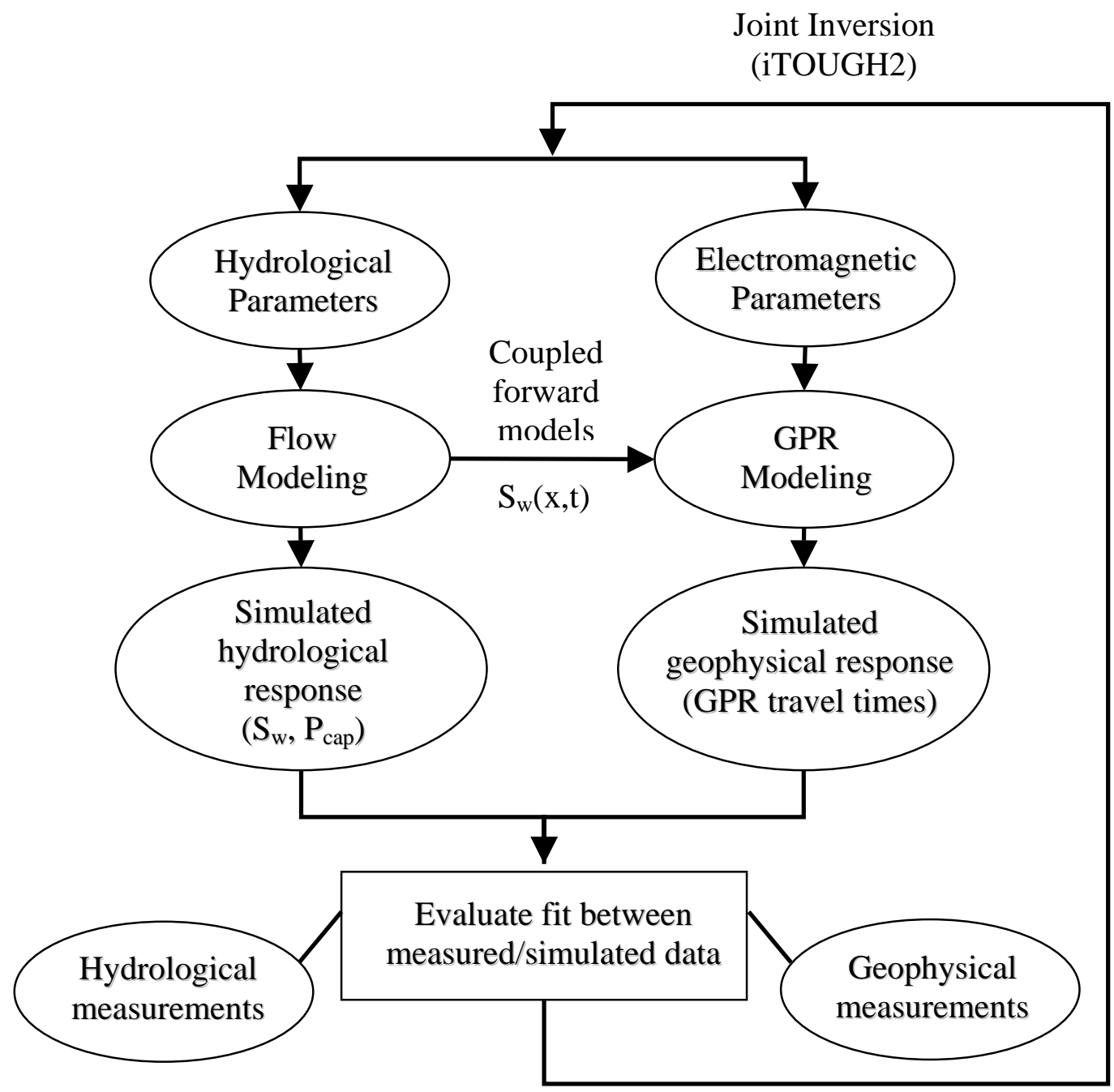

Figure 1. Flow chart for joint inversion of geophysical and hydrological measurements using framework of iTOUGH2 [Finsterle, 1999]. 


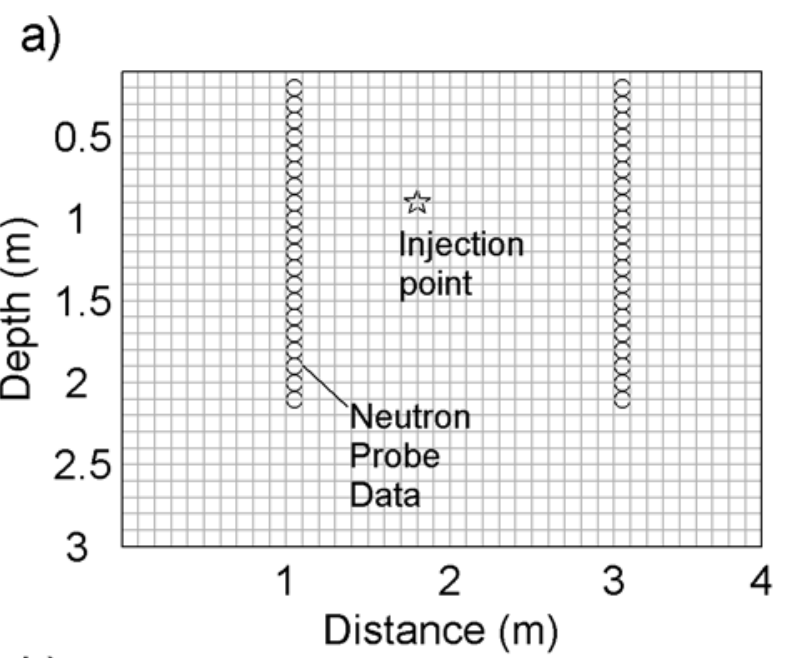

b)

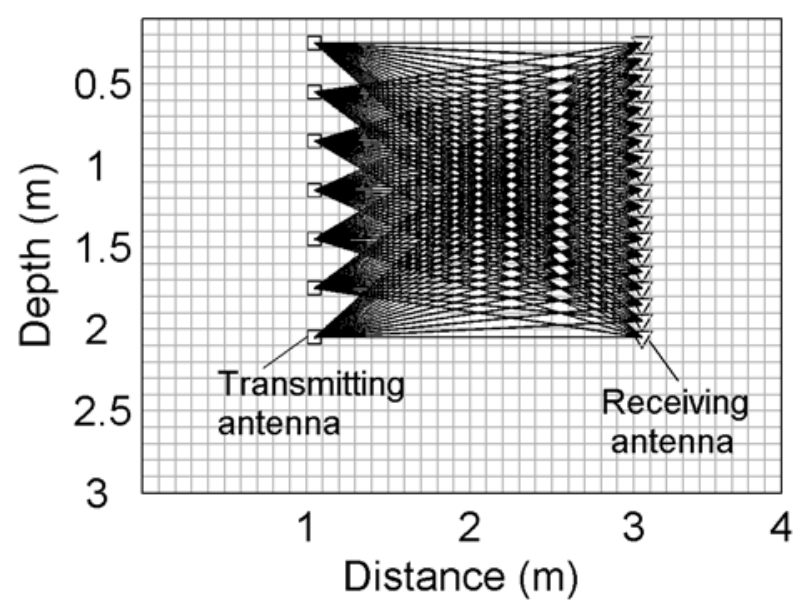

Figure 2. Model geometry for synthetic examples: (a) injection point and neutron probe measurement locations; (b) straight-ray paths and antenna locations. 


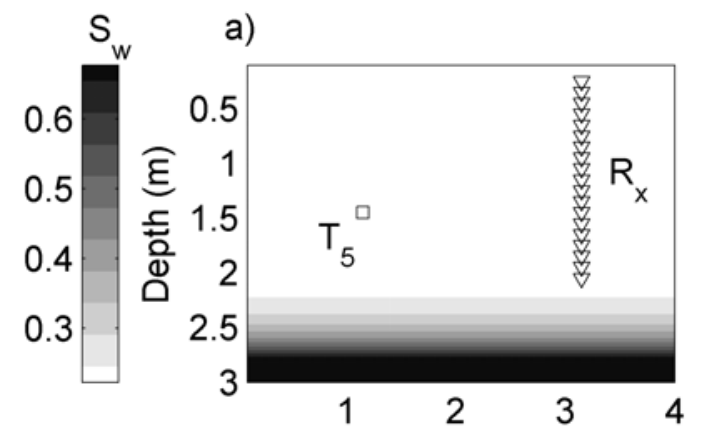

b)

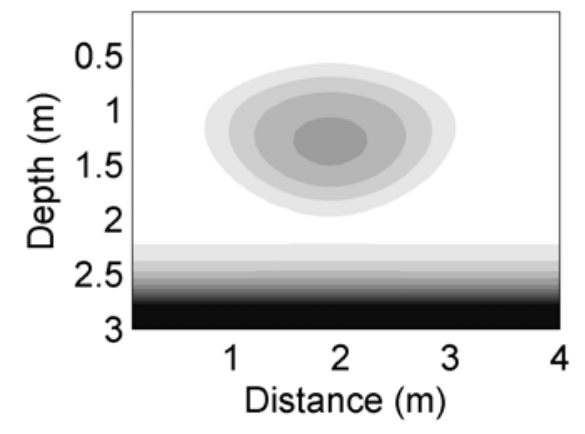

c)

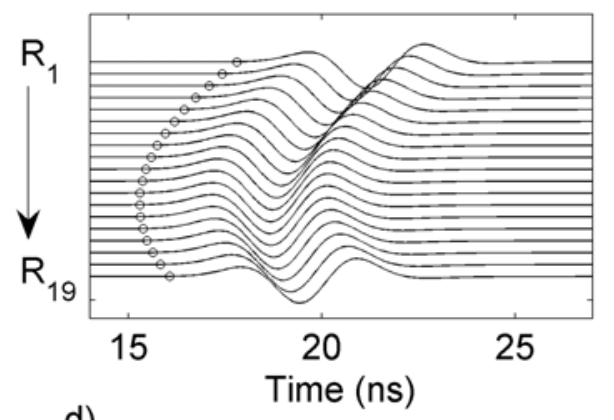

d)

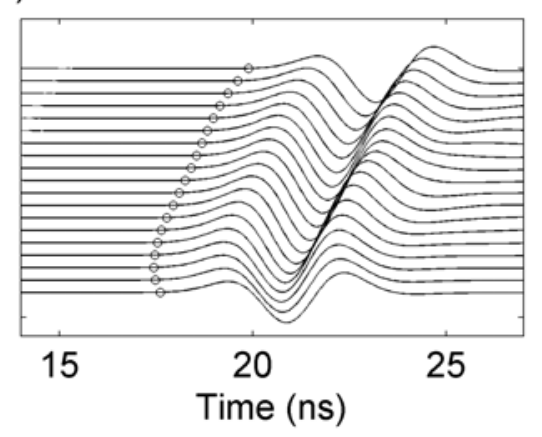

Figure 3. Simulated saturation profiles (a) before injection (steady state) and (b) 18 hours after onset of injection for model with uniform soil parameters. A single transmitting antenna position $\left(T_{5}\right)$ is labeled with a square (there are 7 transmitting antenna positions in all, as shown in Figure 2), which the receiving antenna positions $\left(\mathrm{R}_{\mathrm{x}}\right)$ are labeled with triangles. Simulated waveforms are shown in (c) and (d), corresponding to the simulation times for (a) and (b), respectively. Circles denote the arrival times (before measurement noise is added). 


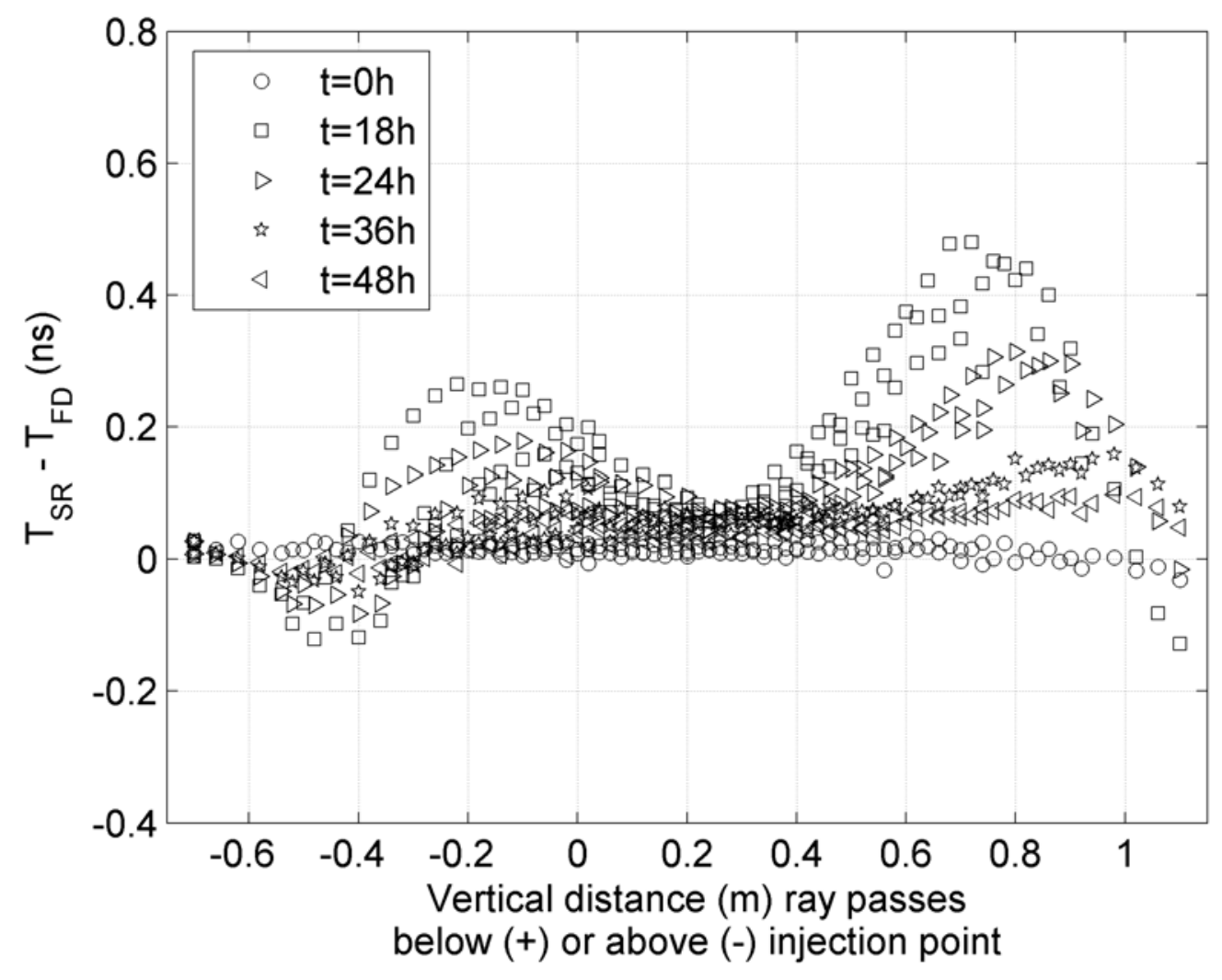

Figure 4. Difference between straight-ray travel times $\left(\mathrm{T}_{\mathrm{SR}}\right)$ and the travel times calculated using a finite difference method $\left(\mathrm{T}_{\mathrm{FD}}\right)$ versus vertical distance by which ray passes above or below injection point (for model with uniform soil parameters). 

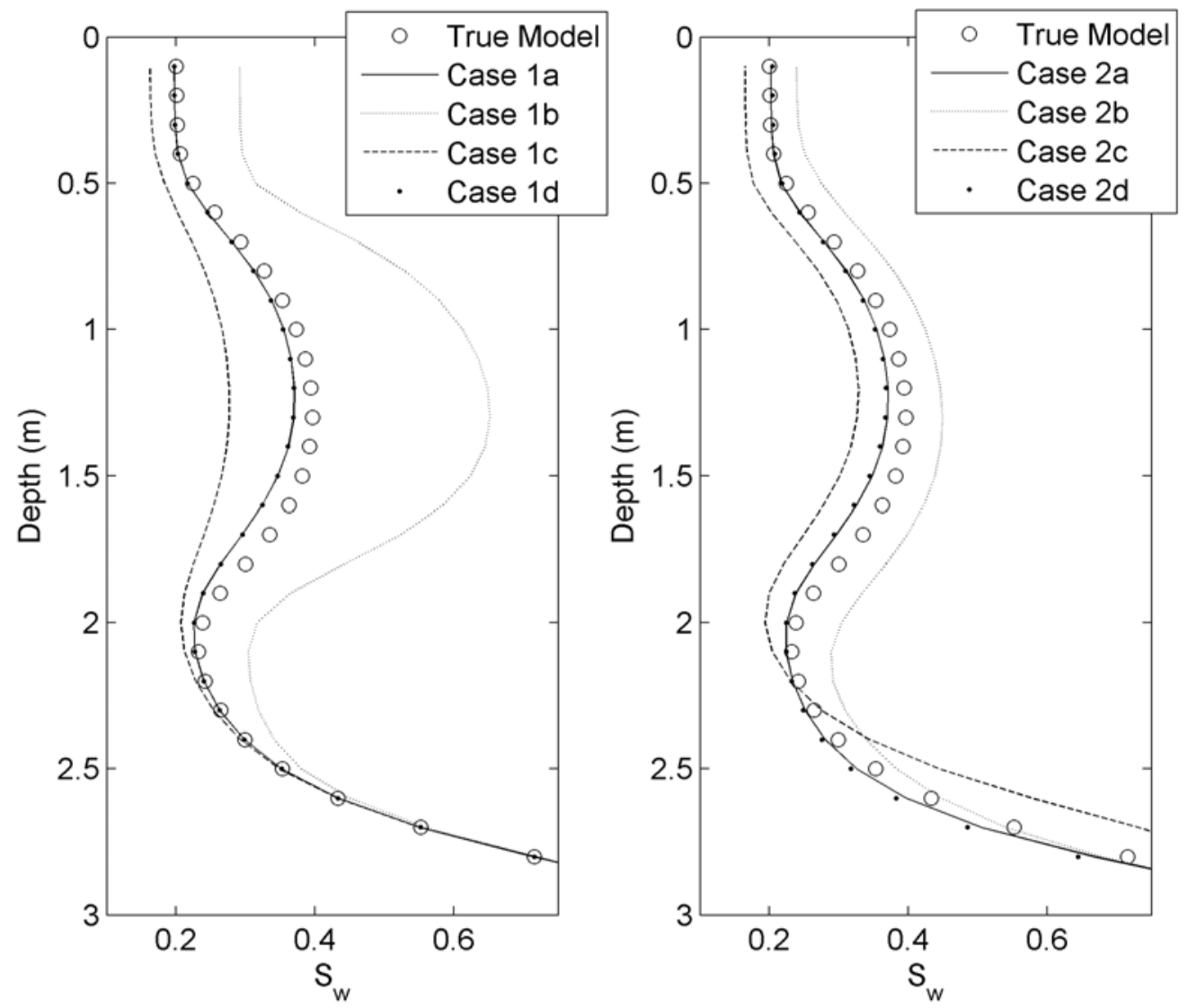

Figure 5. Predicted saturation profiles at 18 hours after onset of injection for Cases 1a-d (left) and Cases 2a-d (right) for example in Section 3.1. The profiles are vertical slices taken from the two-dimensional models at a horizontal distance of $2 \mathrm{~m}$. 

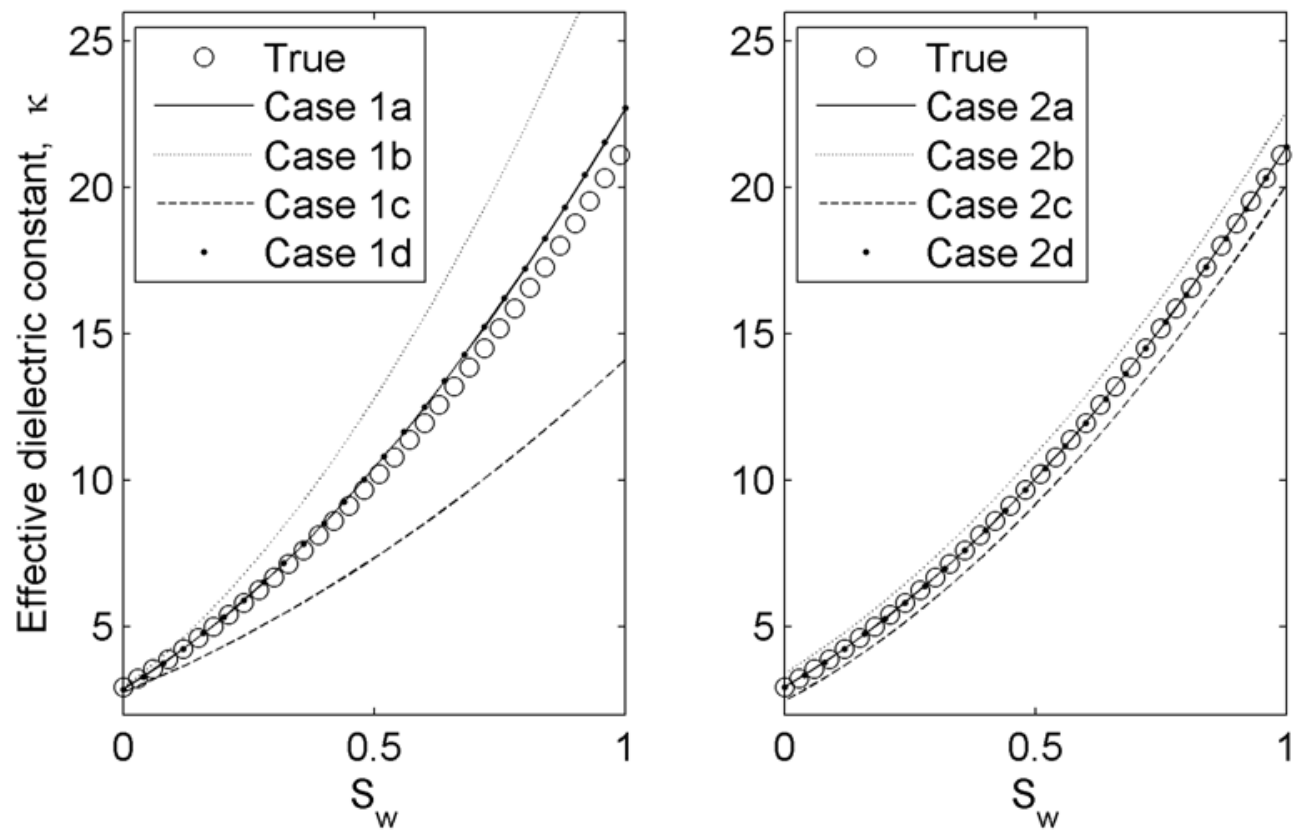

Figure 6. Petrophysical functions for Case 1 (left) and Case 2 (right) of example in Section 3.1. 


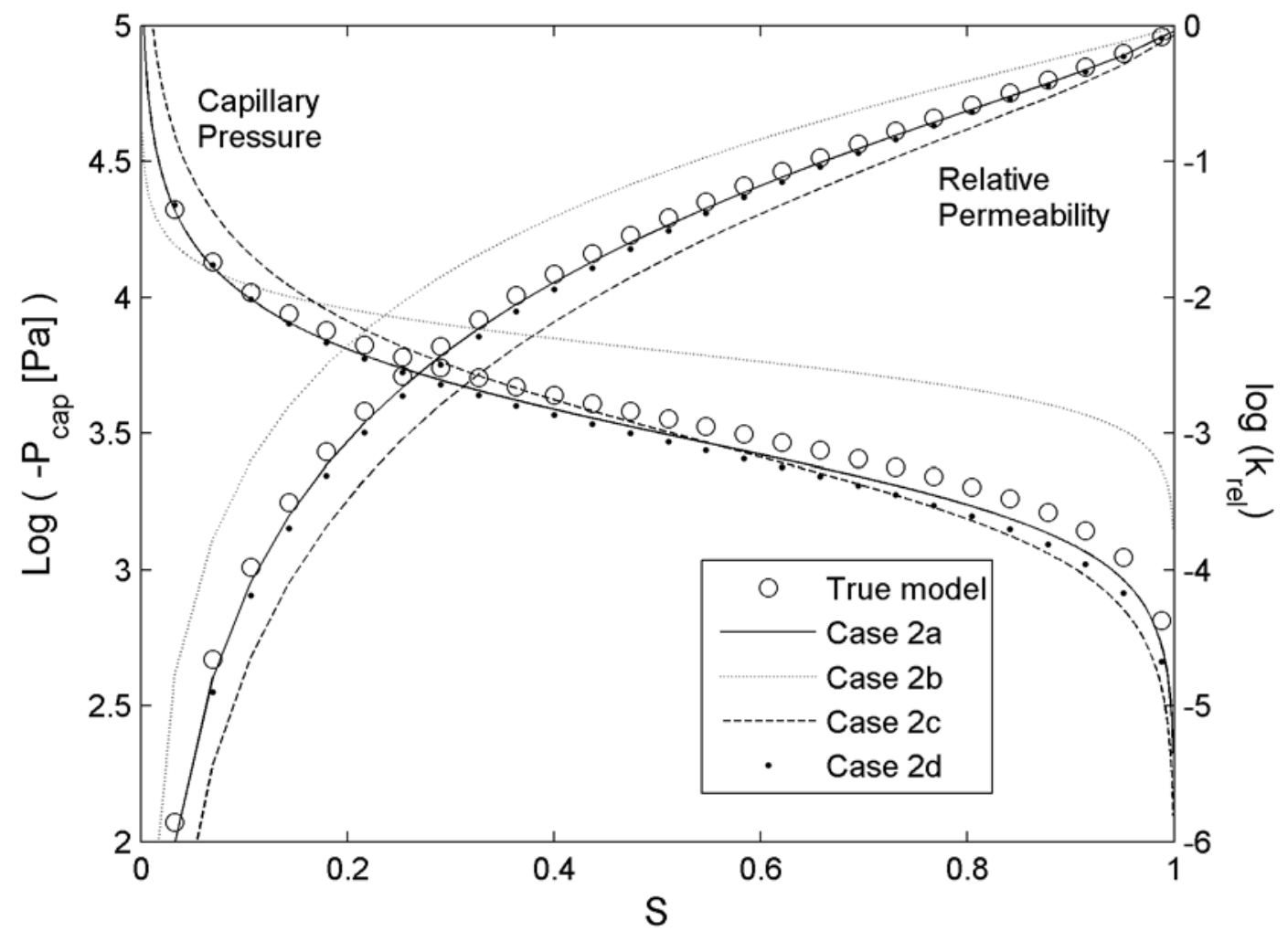

Figure 7. Capillary pressure functions (left axis) and relative permeability function (right axis) for example in Section 3.1. For Case 1, the relative permeability function and the capillary pressure function are fixed to those of the true model (circles). For Case 2, the parameters $\log (1 / \alpha)$ and $m$ of the capillary pressure function and relative permeability functions are estimated through inversion. 

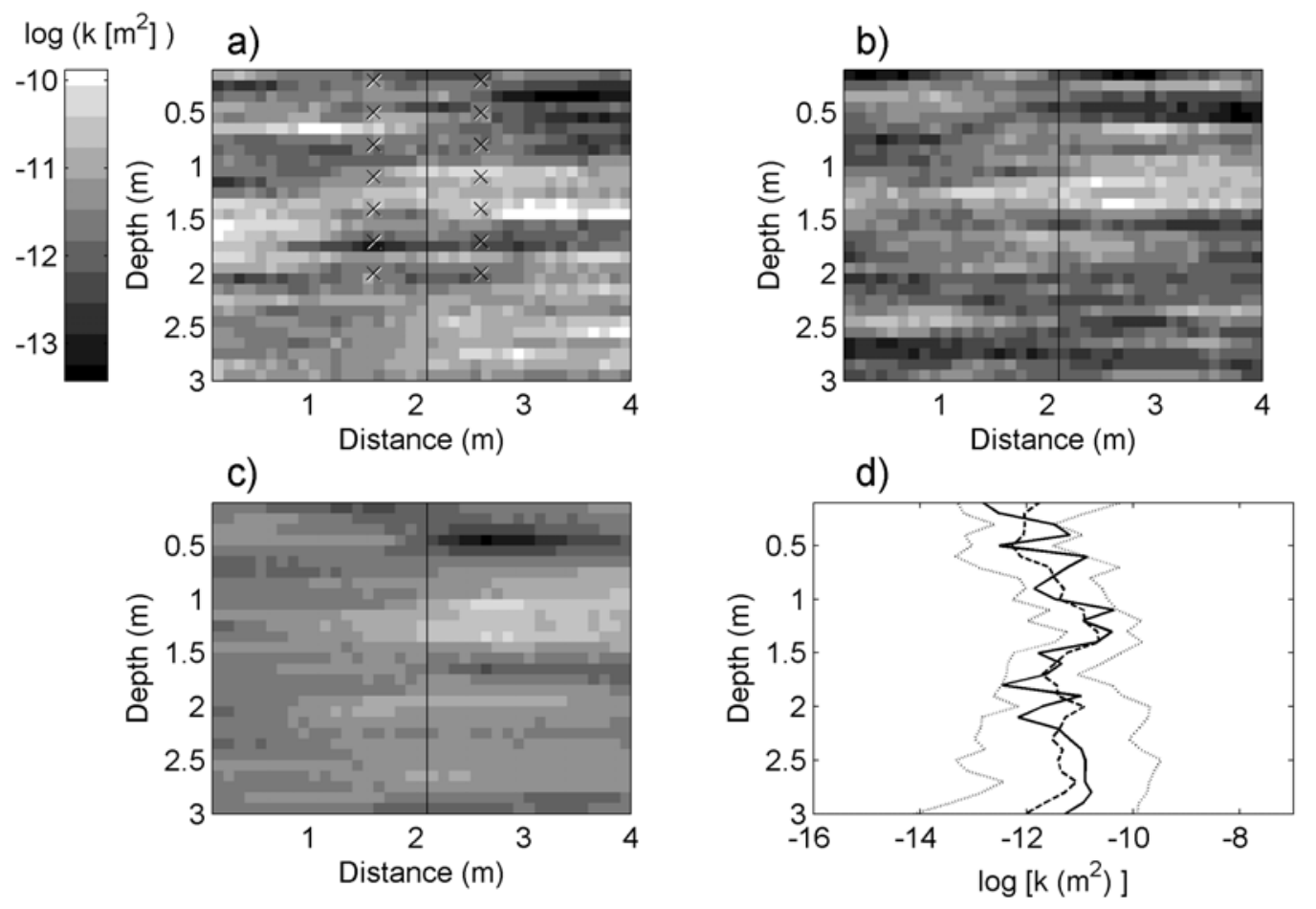

Figure 8. (a) True log permeability distribution for model in Section 3.2, (b) single realization of estimated permeability field, (c) the ensemble mean of the predicted distributions, and (d) vertical cross section showing distribution for true model (solid line), mean of the predicted distributions (dashed line), and the uncertainty bounds for predicted distributions (dotted lines), defined as $+/-2$ standard deviations. The $\mathrm{x}$ symbols in (a) indicate pilot point locations used for inversion. 
a)

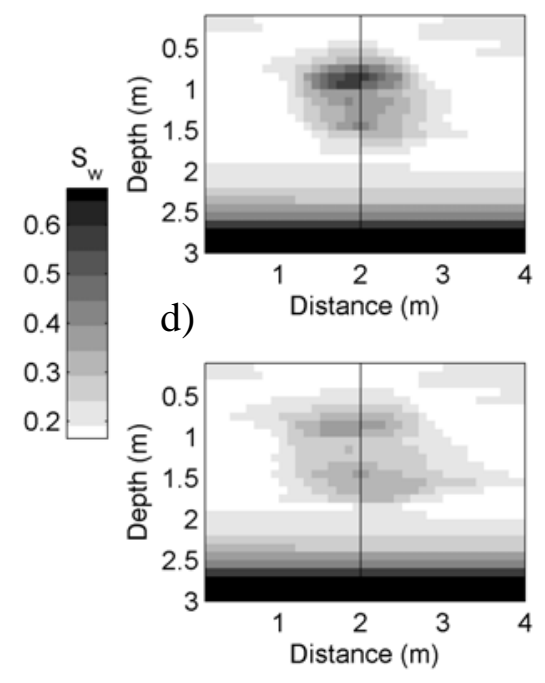

b)

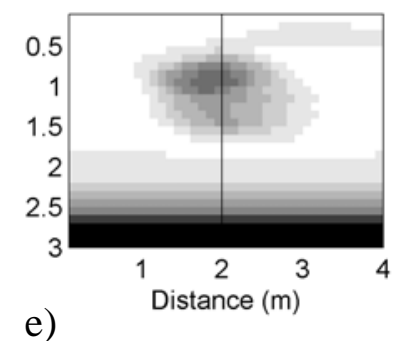

e)

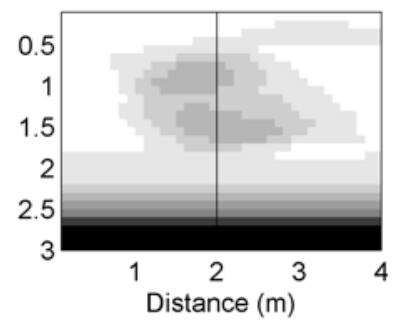

c)

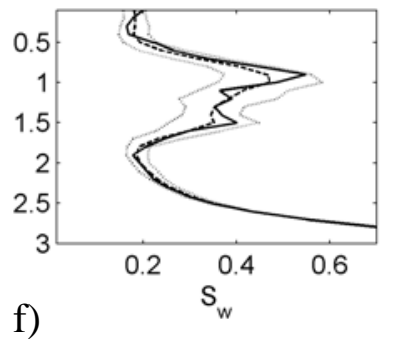

f)

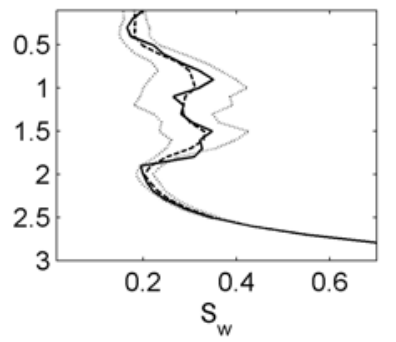

Figure 9. For heterogeneous model (Section 3.2), (a) the distribution of water saturation in the true model, (b) the ensemble mean of the predicted water distributions, and (c) vertical cross section of water saturation for true model (solid line), the average of the predicted distribution of water saturation (dashed line), and the uncertainty bounds (dotted lines) at 12 hours after the onset of water injection. The same cases described in (a)-(c) are shown in (d)-(f) at 24 hours after the onset of injection. 


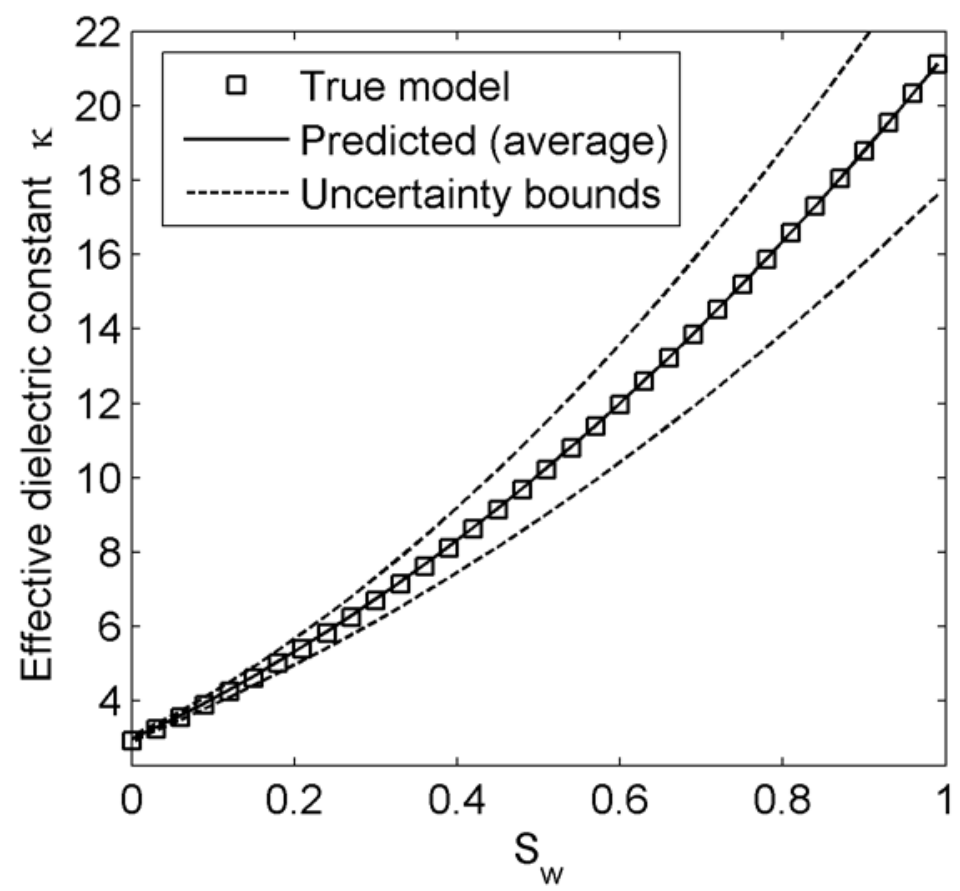

Figure 10. Petrophysical functions for heterogeneous example in Section 3.2: true model (squares); ensemble mean of the estimated petrophysical functions (solid line); and uncertainty bounds (dashed lines), defined as +/- two standard deviations. 


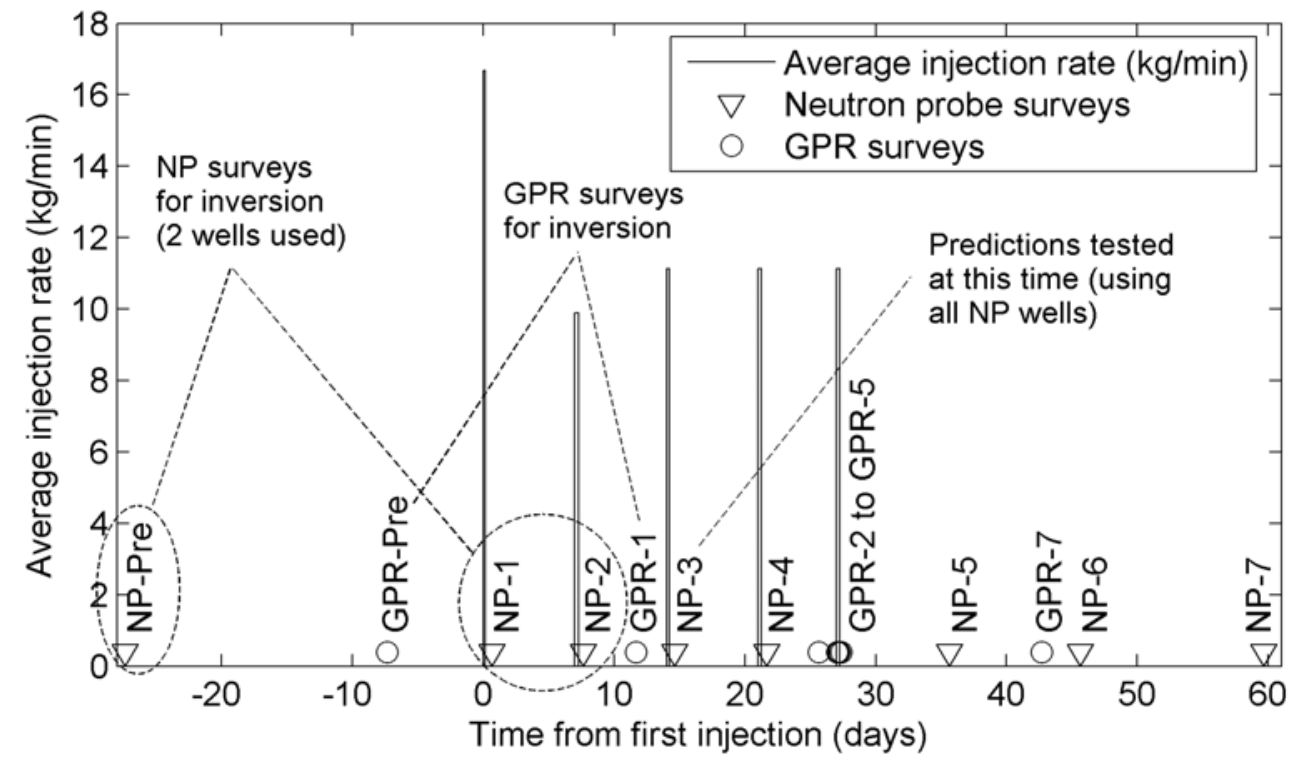

Figure 11. Measurement schedule for injection experiment at Hanford site. NP and GPR data sets were collected before the first injection (NP-pre and GPR-Pre, respectively) and at later times (NP-1 to NP-7, and GPR-1 to GPR-7, respectively). A limited subset of NP data were used for inversion (2 wells indicated in Figure 12 at survey times NP-Pre, NP1, and NP-2). The GPR data sets used for inversion are GPR-Pre and GPR-1. 


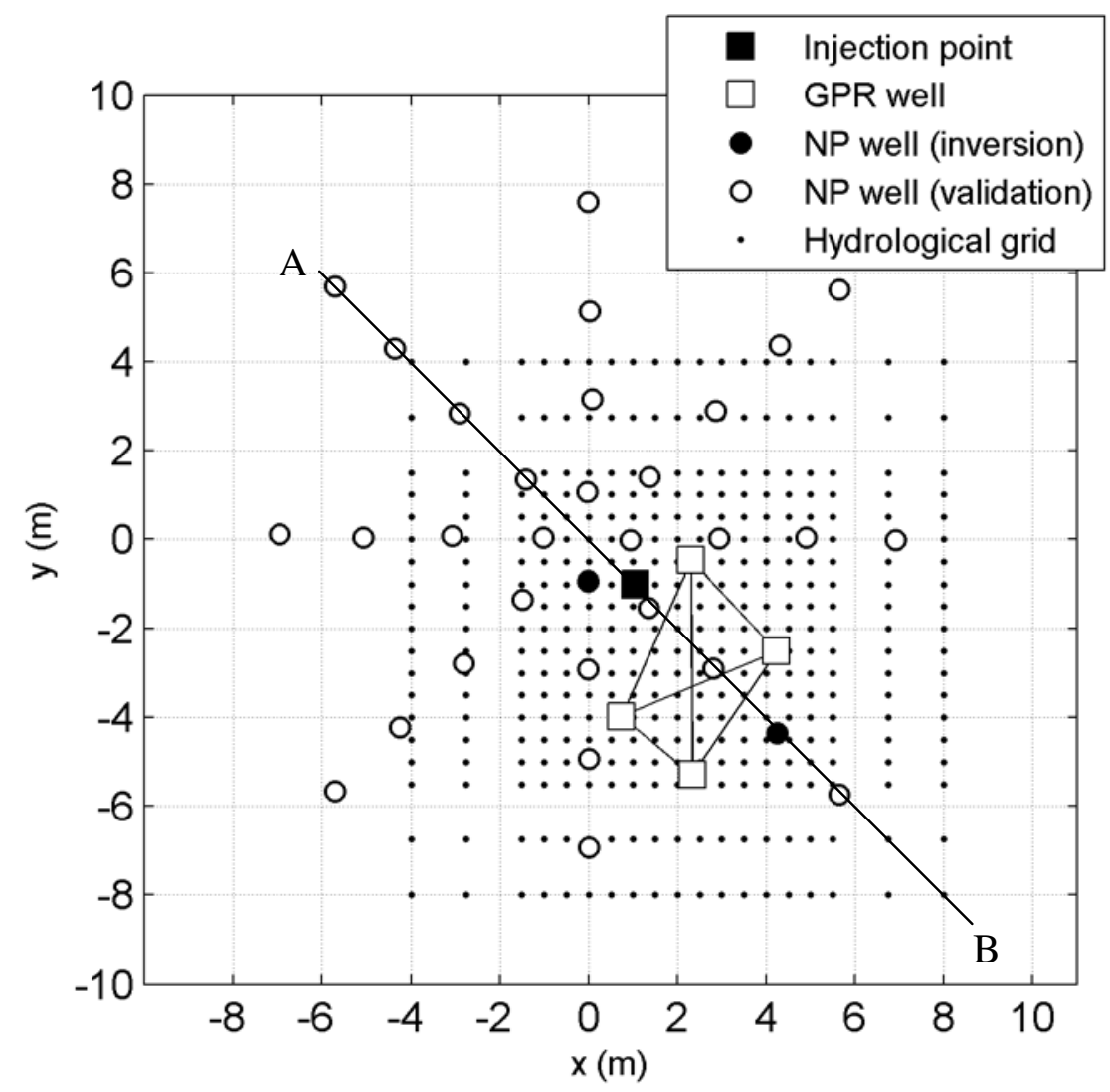

Figure 12. Measurement locations at the Hanford site and plan view of numerical grid used for hydrological modeling. Note that only 2 NP wells (solid circles) are used for inversion, while the remaining $30 \mathrm{NP}$ wells (open circles) are only used to test the inversion results. 
a)

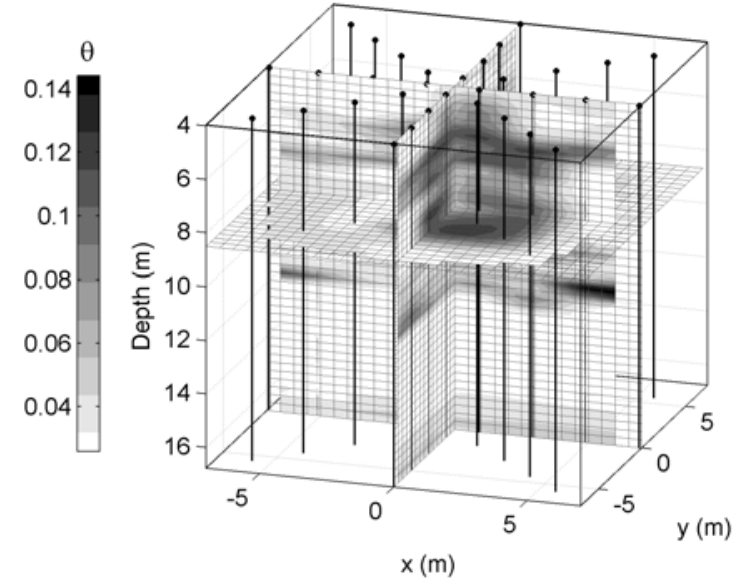

b)

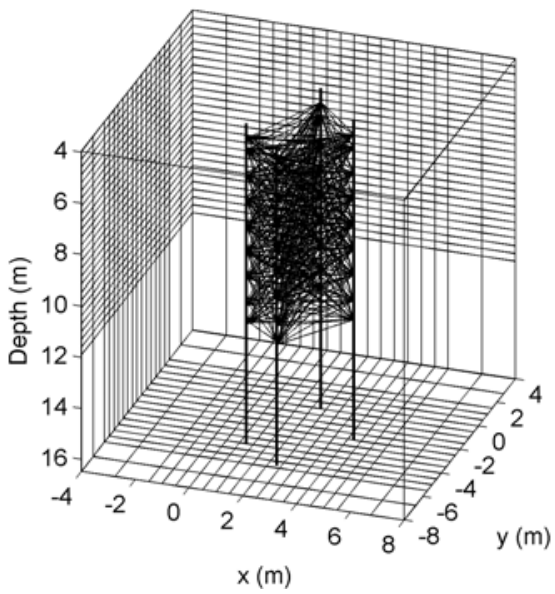

Figure 13. Available data sets collected during injection experiment at the Hanford site: a) example of densely sampled NP data set (interpolated from NP wells, indicated by solid black vertical lines); b) straight ray paths that are formed by the 4 GPR wells are used for inversion. 
a)

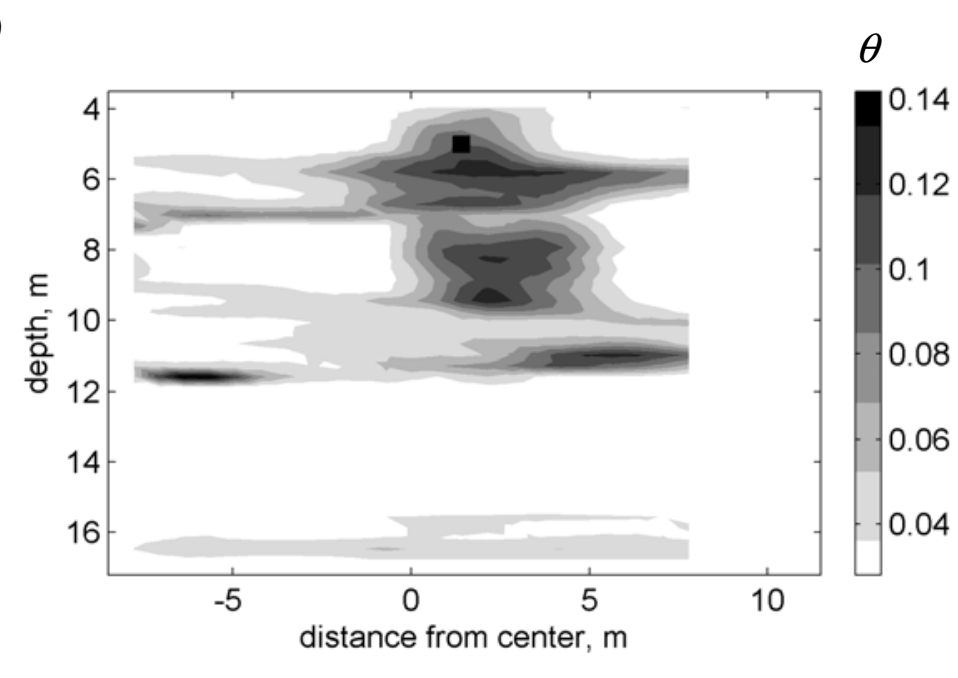

b)

$\theta$

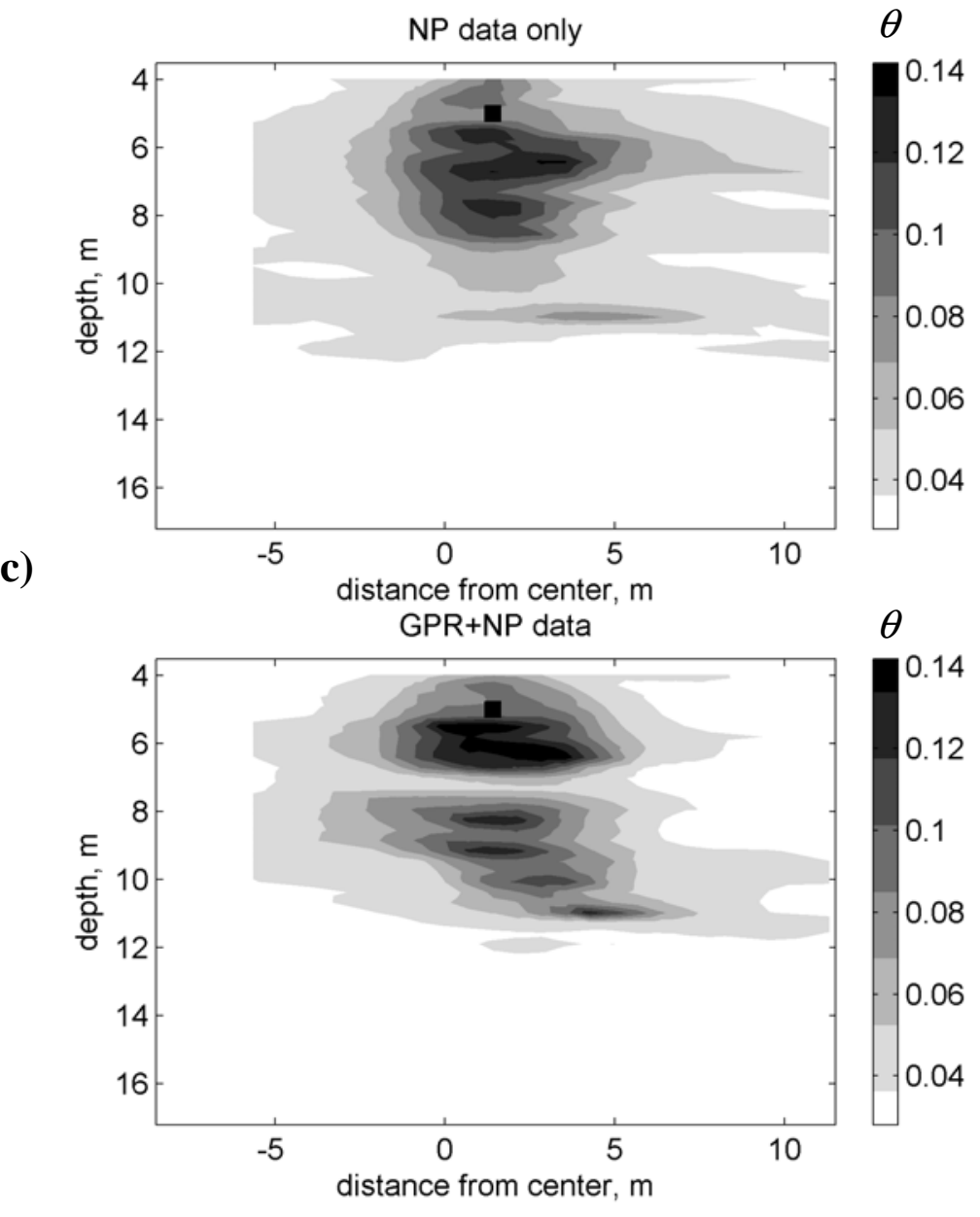

c)

Figure 14. Comparison of water content $(\theta)$ slice $A B$ (see Figure 12) from threedimensional model a) from dense NP data set, and predicted with single inversion realization using b) limited NP data set (using 2 wells at three times), and c) using the GPR data set (collected using 4 GPR wells at two survey times) and the limited NP data set. 

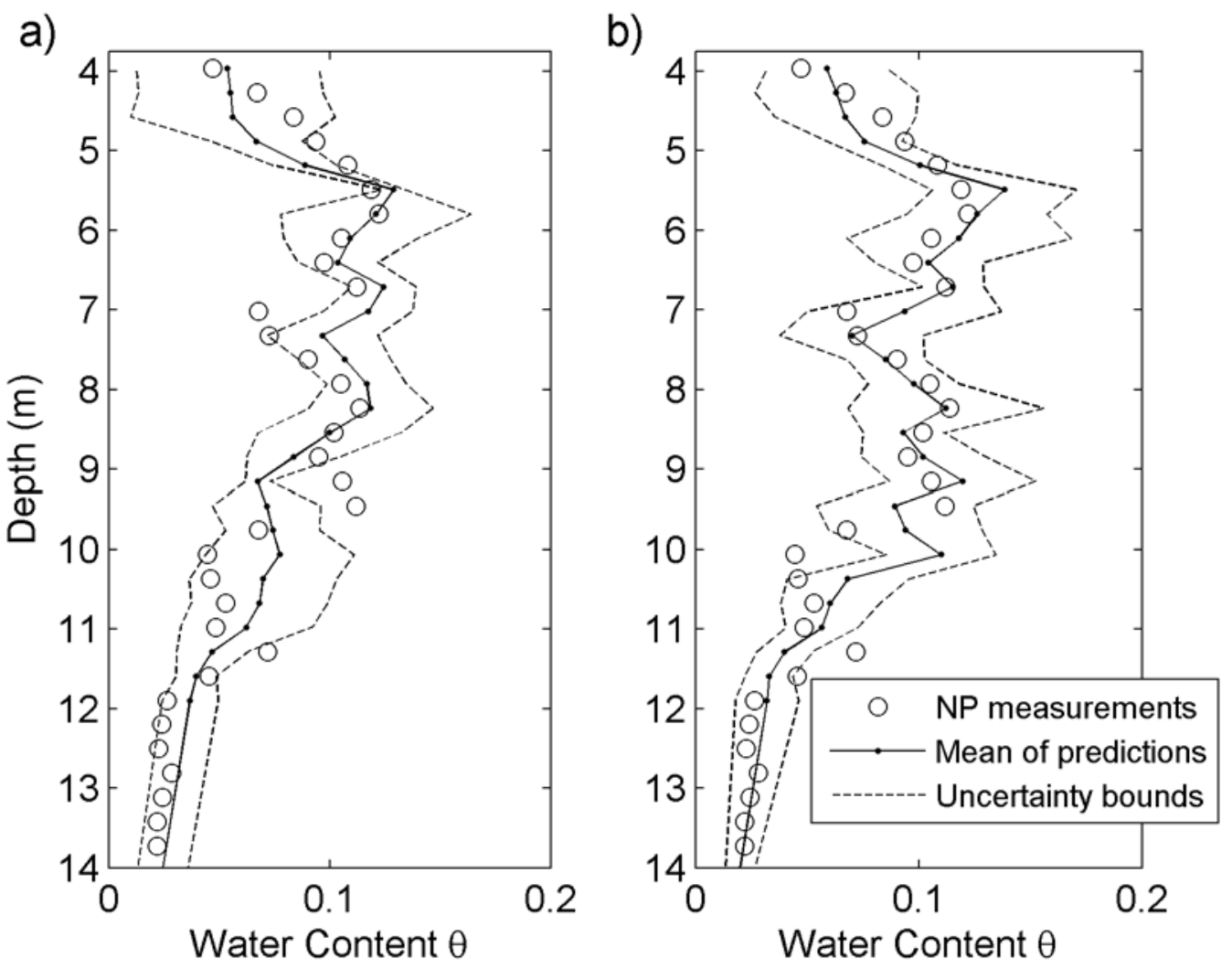

Figure 15. Comparison of water content profile near injection point obtained from dense NP data set (circles) with the mean of the predicted water content profiles (solid line with dots) obtained through inversion of (a) limited NP data set (using 5 wells at three times) and (b) both the GPR data set and the limited NP data set. Note that while NP measurements were collected in 27 wells to obtain the dense NP data sets, only a limited subset of NP measurements are actually used for inversion (see Figure 12); however, all NP data are used to test the inversion predictions. The dashed lines around the mean of the predicted profiles indicate the estimation uncertainty (+/- 2 standard deviations). 